\title{
A REVIEW OF MODELS of
}

\section{RESEARCH UTILISATION}

\section{TRACY BAILEY}

JOHANN MOUTON

\section{crest}

Centre for Research on Science and Technology 
C 


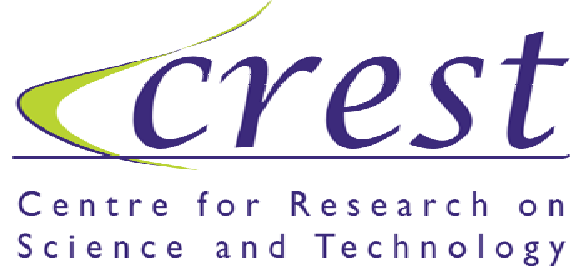

THE PRODUCTION AND UTILISATION OF KNOWLEDGE IN HIGHER EDUCATION INSTITUTIONS IN SOUTH AFRICA

Volume 1

\section{A review of models of research utilisation}

Tracy Bailey \& Johann Mouton

(C)2005 Centre for Research on Science \& Technology, Stellenbosch University

All rights reserved 
The Production and Utilisation of Knowledge in Higher Education Institutions in South Africa (Volume 1): A Review of Models of Research Utilisation

Published by SUN PReSS, a division of AFRICAN SUN MeDIA, Stellenbosch 7600

www.africansunmedia.co.za

www.sun-e-shop.co.za

All rights reserved. Copyright $\odot 2005$ Centre for Research on Science \& Technology, Stellenbosch University

No part of this book may be reproduced or transmitted in any form or by any electronic, photographic or mechanical means, including photocopying and recording on record, tape or laser disk, on microfilm, via the Internet, by e-mail, or by any other information storage and retrieval system, without prior written permission by the publisher.

First edition 2005

ISBN: 978-1-919980-57-7

e-ISBN: 978-1-919980-69-0

DOI: $10.18820 / 9781919980690$

Set in $11 / 13$ Lucida Sans Unicode

Cover design by Dewald van Zyl

Typesetting by Marthie van Niekerk

SUN PReSS is a division of AFRICAN SUN MeDIA, Stellenbosch University's publishing division. SUN PReSS publishes academic, professional and reference works in print and electronic format. This publication may be ordered directly from http://www.sun-e-shop.co.za 


\section{CONTENTS}

Preface

Outline of Volume I

Chapter I: Matters of definition

I.I Different types of research 'use'

I.2 Intended and unintended users of research ......................................... 2

I.3 'Research utilisation' versus 'knowledge utilisation' ............................. 3

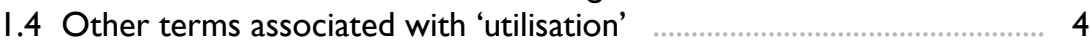

Chapter 2: The emergence and development of knowledge utilisation as a field of inquiry

Chapter 3: Shifts in modes of knowledge production

3.I Developments in higher education …......................................... 10

3.2 Developments in industry

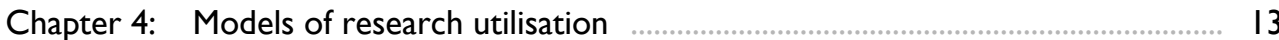

4.I Agricultural extension services ..................................................... 13

Early agricultural extension ............................................... 13

The emergence of modern agricultural extension ................ 13

Agricultural extension in South Africa …............................... 14

Models of agricultural extension ..................................... 17

4.2 The applied social sciences and social policy ...................................... 19

Early models of the utilisation of social research in

policy-making

Critique of earlier models and the emergence of new ideas

4.3 Utilisation of health sciences research for improving practice and bringing about organisational change

Models of research utilisation in nursing practice

Institutionalisation of research utilisation in the health sciences

4.4 The utilisation of science and engineering research for technological development

The linear model of technology transfer and the innovation process

Non-linear models of technology transfer and the innovation process

The importance of 'tacit' knowledge in the process of technology transfer

Ways in which research can be utilised in the innovation process

The institutionalisation of technology transfer 
Chapter 5: Research utilisation: a heuristic framework

5.I Basic precepts of research utilisation

5.2 A heuristic framework of knowledge production and utilisation

Some basic distinctions

The contingency effectiveness model of technology transfer (CETT) 


\section{PREFACE}

In June 2002, the Carnegie Corporation of New York awarded a substantial grant to CREST - then the Centre for Interdisciplinary Studies - to conduct research on the production and utilisation of research in higher education in South Africa.

In the original proposal to Carnegie, we described the context and rationale behind this project as follows:

With the advent of the new democracy in 1994, it was expected that the higher education institutions in the country would and should play a major role in the transformation of South African society. On the one hand, South African universities and technikons were expected to transform themselves; on the other hand, as major actors within the national system of innovation, it was also expected that they would make a significant contribution to the new society in various ways, including the production of relevant and useful knowledge.

The focus in the project is on the R\&D function of higher education institutions; on the knowledge produced by scientists and scholars at these institutions. In terms of this focus, the overarching aim of the proposed project is to analyse and assess to what extent South African universities and technikons are engaged in a transformative agenda in the production and utilisation of scientific knowledge.

Two major research questions will drive the project:

$<$ To what extent has the production of scientific knowledge at SA universities and technikons changed over the past seven years?

C To what extent is the knowledge produced at SA universities and technikons used, particularly in the interest of new national goals?

At the same time as we commenced our work on this project, the National Advisory Council on Innovation placed on tender a national study on the state of research utilisation in South Africa. CREST was awarded a grant to conduct a survey of public sector R\&D as well as a separate interview-based study of industry views on research utilisation. We subsequently integrated our work on the Carnegie project and the $\mathrm{NACl}$ commission into a two and a half year study. By the end of December 2004 we completed our research.

The findings of this study have been organized into six separate reports:

Volume I: A review of models of research utilisation

Volume 2: A survey of research utilisation

Volume 3: An industry study of the utilisation of public R\&D

Volume 4: The dynamic of knowledge production and utilisation: Fifteen case studies

Volume 5: The role of intermediary organisations in the utilisation of research

Volume 6: Knowledge for transformation: Modes of knowledge production and utilisation in post-apartheid South Africa 


\section{Outline of Volume 1}

This review of the literature on knowledge and research utilisation was conducted to inform the empirical studies (reported in Volumes 2 and 3). The review has been structured according to five themes:

$<$ Terminological issues: an overview of key terms such knowledge utilisation, use, and uptake including distinguishing between different forms of research utility.

$<$ A short discussion of the rise of "knowledge utilisation" as a domain of scholarship

$<$ A brief overview of recent discussions of shifts in modes of knowledge production

< More detailed sections on different "approaches" or "models" of research utilisation in the following fields -

- Agriculture

- Applied social sciences and policy studies

- Health sciences

- Engineering sciences and technological development

< A concluding discussion of a "heuristic" framework that attempts to integrate the key issues discussed in this report.

The authors wish to thank all the staff of the Centre for Research on Science and Technology who have assisted in the compilation of this report. We wish also to point out that Section 4.4 of this report owes much to another report of the Centre of which Ansie Carstens was the main author.

TRACY BAILEY and JOHANN MOUTON

Stellenbosch 


\subsection{Different types of research 'use'}

The term 'research utilisation' can be understood either in a narrow or broad sense. In the narrow sense, the utilisation of research refers to the economic or commercial utility of research, i.e. how science is useful for economic growth or commercial aims. In the broader sense, research utilisation refers to any form of use that scientific research (results) is put to. So, in addition to economic or commercial utility, we could also include social utility (use of research for society at large) and political utility (science in support for political decision-making). We will refer to these as non-epistemic forms of utilisation.

However, even this broadening of the meaning does not cover all possible forms of research use. We also need to remind ourselves that science (at least 'basic' or 'fundamental' science) is first and foremost aimed at the advancement of knowledge and increasing our understanding of the world. Some would argue that no use is intended or anticipated within a fundamental science paradigm. This is only true if 'use' is reserved for the narrow meaning of 'economic' or 'applied' use. But other scientists of course, use fundamental science. One scientist 'uses' another's findings or uses a model or framework developed by another. We often talk about 'applying' the insights gained in one study to another. We will refer to this as the epistemic utility of scientific research: research for the sake of (producing) knowledge.

Research utilisation can also be understood in terms of direct (immediate) and indirect (mediated) uses of research. Research (findings) are often used immediately, such as when advice is given and acted upon, when research is used to inform decision-making, or when research leads to changes in an existing technology or the development of a new one. In all of these cases, a clear 'causal chain' or 'causal network' links the publication or dissemination of the research to the ensuing decisions.

However, very often research is published and made public in various forms without any immediate uptake. The findings might lie dormant in the public domain until some time in the future when it is 'rediscovered'. This applies both to epistemic and non-epistemic uses of research. There are many examples of scientific ideas which are not immediately appreciated and applied/used but only later taken up by the scientific community (Wegener's continental drift theory is a good example).

Similarly, scientific ideas - especially in the social sciences and humanities - sometimes take a long time and follow indirect routes of diffusion before being applied in a social or economic or political sense. Carol Weiss's well-known phrase "knowledge creep" is a good description of such indirect utilisation. Weiss (1980, quoted in Waardenburg 2001:9; original emphasis) observes that research usually influences policy in diffuse ways - it provides "a background of empirical generalizations and ideas that creep into policy deliberations." Another example is the way in which social science terms such as "Freudian slip" or "paradigm shift" eventually became part and parcel or our everyday 
discourse, and are now used in contexts very different from the original intentions of their authors.

In the social science domain, various authors have identified different types of research 'use', namely instrumental, conceptual and symbolic (see Beyer \& Trice 1982:598-601; Neilson 200 I:8). Instrumental use corresponds with direct (mediated) used described above. Here, research findings are used, for example, to inform the development of a new programme or to solve a policy problem. In the nursing context, Estabrooks (1999:204) defines instrumental use as "a concrete application of the research, and the research is normally translated into a material and useable form, such as a protocol. The research in this case is used to make specific decisions/interventions."

Conceptual use, on the other hand, refers to the ways in which research findings 'infiltrate' policy-makers' thinking over time, raising their awareness of issues in a broader sense. This links to Weiss's notion of the 'enlightenment' function of social research, which we discuss in detail in Section 4. Finally, symbolic use "involves the use of research as a persuasive or political tool to legitimate a position or practice" (Estabrooks 1999: 204).

\subsection{Intended and unintended users of research}

The notion of 'utilisation' logically presupposes that some user or users have recognised the utility/usefulness of research. The notion of 'use' (as opposed to 'awareness') implies some action. We become aware or are made aware of new scientific discoveries or inventions. Nevertheless, in applying or using other scientists' work, we have to take an action; it involves a deliberate decision on our part.

We can distinguish between intended and unintended users of research. Those who were the original intended users, e.g. a contracting agency, government department, commissioning firm, etc, often use research. However, research - being (mostly) in the public domain - can in principle be appropriated and applied by any person or persons who find it useful. This is especially true when we talk of the epistemic utility of research. Scientists normally do not have specific scientists in mind when disseminating their research findings to the larger scientific community. Moreover, even if they have a specific disciplinary grouping or theoretical paradigm in mind, it does not prevent any other scientist or scholar from using, applying and even adapting those findings in a way that they deem useful. 
The distinctions made thus far can be summarised as follows:

Table I: Utilisation: Conceptual distinctions

\begin{tabular}{|c|c|c|c|c|}
\hline \multirow{2}{*}{$\begin{array}{l}\text { FORMS OF } \\
\text { UTILITY }\end{array}$} & \multicolumn{2}{|l|}{ INTENDED USERS } & \multicolumn{2}{|c|}{ UNINTENDED USERS } \\
\hline & $\begin{array}{l}\text { Immediate / direct } \\
\text { use }\end{array}$ & $\begin{array}{l}\text { Mediated / } \\
\text { indirect use }\end{array}$ & $\begin{array}{l}\text { Immediate / direct } \\
\text { use }\end{array}$ & $\begin{array}{l}\text { Mediated / indirect } \\
\text { use }\end{array}$ \\
\hline $\begin{array}{l}\text { Epistemic or } \\
\text { scientific utility }\end{array}$ & Applied research & & $\begin{array}{l}\text { Basic research } \\
\text { Immediate scientific } \\
\text { uptake }\end{array}$ & $\begin{array}{l}\text { Basic research: } \\
\text { medium- to long- } \\
\text { term scientific } \\
\text { uptake (e.g. } \\
\text { Wegener) }\end{array}$ \\
\hline $\begin{array}{l}\text { Non-epistemic } \\
\text { utility (social, } \\
\text { economic, } \\
\text { commercial) }\end{array}$ & $\begin{array}{l}\text { Technological } \\
\text { development / } \\
\text { product } \\
\text { development } \\
\text { commissioned }\end{array}$ & $\begin{array}{l}\text { Technology } \\
\text { imitation }\end{array}$ & $\begin{array}{l}\text { Basic strategic } \\
\text { research: immediate } \\
\text { social and political } \\
\text { uptake (e.g. } \\
\text { Gibbons thesis) }\end{array}$ & $\begin{array}{l}\text { Knowledge creep: } \\
\text { diffusion into } \\
\text { society / economy } \\
\text { Knowledge } \\
\text { spillovers }\end{array}$ \\
\hline
\end{tabular}

The information in the cells of the table refers to modes of knowledge production or types of research and development (R\&D). This tabulation is useful because it clearly illustrates a basic precept about research utilisation, viz. the direct relationship between modes of knowledge production and forms of research utilisation. We return to this theme later in this review.

However, the summary above should not be interpreted to mean that there are hard and fast boundaries between intended and unintended users, or between immediate and mediated use. The latter is clearly a continuum. At the one end of the spectrum, forms of research utilisation are immediate: scientific advice and consultation, a technical briefing, a presentation to a scientific or non-scientific audience, and so on. At the other end, one finds that research findings seep into knowledge and other social systems slowly and in complex ways. The transfer of sophisticated technologies from the producer to the ultimate end-user is a complex process that involves overcoming many obstacles (financial, legal, social, cultural, institutional) as well as the involvement of multiple stakeholders.

In addition to the distinctions made above, it is useful to briefly discuss other distinctions and definitions found in the literature.

\section{3 'Research utilisation' versus 'knowledge utilisation'}

Another recurring theme revolves around the distinction between 'research utilisation' and 'knowledge utilisation'. While these terms are often used interchangeably in the literature, some theorists argue for a distinction. Backer (1991:226-227), for example, suggests that

Knowledge utilization' includes research, scholarly, and programmatic intervention activities aimed at increasing the use of knowledge to solve human problems. The field embraces a number of subtopics, each of which 
has its own body of work and professional tradition. These various sub fields overlap, so an 'umbrella definition' of the field is necessarily imprecise.

For Backer (1991:227-228), the subtopics within the field of knowledge utilisation include technology transfer (hard and soft), information dissemination and utilisation, research utilisation, innovation diffusion, the sociology of knowledge, organisational change, policy research, and interpersonal and mass communication. In this sense, research utilisation is one aspect of the broader process of knowledge utilisation. Following a similar logic, Estabrooks (1999:204) describes research utilisation as a "specific kind of knowledge utilization":

The knowledge, using Carper's (1978) classification, is primarily empirical in nature, but may also be aesthetic or ethical, if those forms of knowledge have a research base to substantiate them. It is a complex process in which knowledge, in this case in the form of research, is transformed from the findings of one or more studies into possible nursing interventions, the ultimate goal of which is use in practice. The research may or may not be translated into a product, that is, a material form such as a clinical protocol, a clinical decision algorithm, or a clinical practice guideline.

It is clear that the protagonists for or against either terminology work with more or less inclusive definitions of 'research'. If 'research' were understood in a limited empirical sense of the word, then it would make sense to rather use the term 'knowledge' so as also to include theoretical knowledge and other forms of non-empirical inquiry (e.g. philosophical inquiries, hermeneutical insights). However, if research is understood in a very inclusive sense to refer to all forms of (scientific) investigation, then the difference between research and knowledge utilisation becomes negligible. We will use these terms interchangeably although in some cases - where we deliberately wish to emphasize the more inclusive use of 'knowledge' - we will use the term 'knowledge utilisation' (cf. Section 2).

\subsection{Other terms associated with 'utilisation'}

Finally, writers both within and between different science cultures also employ a range of other terms to refer to what we here are calling research utilisation. For instance, in some cases, 'utilisation' and 'use' are used interchangeably. In other cases, words such as 'uptake', 'adoption', 'translation' or 'appropriation' are used instead. Yet others frame their discussions of research utilisation in terms of the 'value' or 'benefits' of research to economies, and to societies as a whole. Beyer \& Trice (1982:597-598; original emphasis) provide definitions for some of these terms:

At least three sets of behaviors are involved in generating actions from research. Adoptions occur when decision makers in user systems use research results or prescriptions derived from them to decide what to do. Use occurs when members of user systems act to implement decisions based on research results and prescriptions. Institutionalization occurs when actions implementing decisions based on research results and prescriptions become part of the expected and customary routines for doing things in user systems. 
In the natural science and engineering fields, research utilisation is usually described in terms of 'technology transfer' or the 'innovation process'. It will become clear in later sections of this paper that different types of 'research' and 'knowledge' and the contexts within which they are produced and utilised, give rise to different forms of utilisation. Many of these terms will be unpacked in detail and located within their theoretical frameworks. 
CHAPTER 2

THE EMERGENCE AND DEVELOPMENT OF KNOWLEDGE UTILISATION AS A FIELD OF INQUIRY

The idea of applying knowledge or using the results of inquiry is not new. In 1979, Robert F Rich observed that the "notion of adapting knowledge to the needs of society dates back to the Greeks and is a theme running through much of Western thought" (quoted in Backer 1991:228). Albæk (1995:79) also writes about the link between social research and policy-making which has been a common theme in Western philosophy:

Plato thought that knowledge and power should be concentrated in the hands of 'philosopher-kings'. One of the founders of modern social science, Auguste Comte, thought that the power to govern should be given to the socalled 'positive priesthood' of modern society, i.e. the scientists. And in our own day there is still a widespread idea that it should be possible to apply scientific insight to the solution of the many problems we and our society face today.

According to Backer (1991:228), the history of knowledge utilisation as a field of inquiry dates "back to the European beginnings of social science, with Gabriel Tarde's 'Laws of Imitation' and early anthropologists known as the British and German-Austrian 'diffusionists'." He indicates that the first real sign of knowledge utilisation activities in the United States emerged in the 1920s with various studies "concerning the diffusion of agricultural innovations to farmers and of new teaching ideas to school personnel" (Backer 1991: 228-229). We consider the agricultural extension model in a later section as one of the earliest models of utilisation that emphasised the dissemination of research findings.

The period after the Second World War saw the arrival of the so-called 'information age' and the widespread increase in knowledge production characteristic of 'knowledge-based economies' (Backer 1991:228-229). (We expand on this later.) According to Backer (1991:229), the "production of more knowledge increased motivation to devise and test strategies for promoting its wider use."

However, knowledge utilisation as a field of inquiry really started to take shape in the 1970s. Firstly, a number of researchers, mainly in the United States, conducted empirical studies, many of which focused on the uses of social research in public policymaking (Beyer \& Trice 1982:594).

Secondly, various federal agencies in the US launched programmes and offices dedicated to improving the dissemination, utilisation and adoption of innovations by individuals and organisations (Backer 1991:229). Utilisation studies were conducted and dissemination and utilisation strategies were tested. In addition, various non-profit research institutes and university-based programmes were established, such as the Center for Research on the Utilization of Scientific Knowledge at the University of Michigan, and the University of Florida Rehabilitation Research Institute on Research Utilization (Backer 1991:230). It was also during this period that the field of 'programme evaluation' emerged in the US in 
response to the need for empirical studies into the impact and benefits of large government programmes (Backer 1991:229).

According to Backer (1991:229), the US federal government's interest in knowledge utilisation

... came from three principal sources: (a) the desire for rapid technological change to stimulate greater economic growth; (b) a desire to enhance the transfer of technology emerging from defense and space-related research; and (c) a desire to promote the adoption of innovations emerging from research and demonstration funding provided by federal health, education, and human services agencies.

Finally, the professionalisation and further institutionalisation of knowledge utilisation as a domain of inquiry during this period was supported by the introduction of three journals: the Journal of Technology Transfer in 1975, Knowledge in 1979 and Knowledge in Society in 1988. In addition, two professional societies were established, namely the Technology Transfer Society (1975) and the Knowledge Utilization Society (1985).

Even this very cursory overview of the emergence of 'knowledge utilisation' as a 'field' or 'discipline' of inquiry, shows quite clearly how different discourses developed within the different science domains. The issue of knowledge utilisation in applied social science was - and continues to be - linked either to policy research (or policy analysis) or to programme evaluation studies. The common thread is that both policies and programmes are human interventions that are best based on some prior research. Evidence-based policy-making or programme development establishes a direct link between social science research and social interventions.

Within the natural and engineering sciences, knowledge utilisation was always understood within a broader framework of innovation studies. As we will see later, this is due - amongst other things - to the early predominance of the linear model of innovation, which presumed a direct causal link between basic and applied research, and technological innovation and commercialisation. Within these discourses the questions revolved around understanding the process that leads from scientific inventions and discoveries (fundamental science) to new technologies.

Of course, if one accepts that social policies and interventions are the human science equivalents or 'analogues' of (natural science) technologies, then the issues raised in these different domains are not so different. 


\section{CHAPTER 3}

\section{SHIFTS IN MODES OF KNOWLEDGE PRODUCTION}

It is not possible to fully understand the history and different models of research or knowledge utilisation without also taking into consideration recent trends in debates about the nature of knowledge production. The aim of this section is to summarise some of the main trends in the nature of public science as observed and discussed by various commentators.

There is remarkable convergence of opinion in the literature regarding the major trends in public (government-supported) science in most industrialised countries over the past five decades. Well-known scholars such as Henri Averch, Stuart Blume, Aant Elzinga, Christopher Freeman, Arie Rip and others concur, not only about the periodisation, but also about the main trends and shifts that characterise public sector R\&D in the post-war period.

Ruivo's overview is summarised in Table 2. As is evident from the table she distinguishes between three main phases or paradigms in international R\&D. Within each paradigm Ruivo identifies the key contexts within which R\&D was produced, the underlying model of technological change, topical issues that were discussed and the predominant type of research.

\section{Table 2: $\quad$ Trends in international R\&D}

\begin{tabular}{|c|c|c|c|c|c|}
\hline & 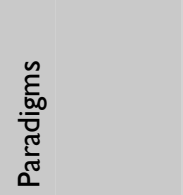 & 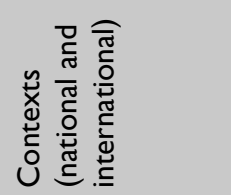 & 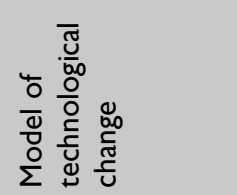 & 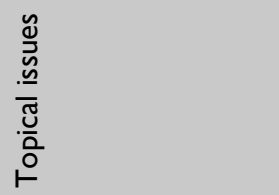 & 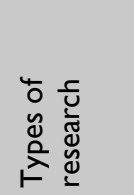 \\
\hline $\begin{array}{l}1945- \\
1970\end{array}$ & $\begin{array}{l}\text { Science as } \\
\text { motor of } \\
\text { progress }\end{array}$ & $\begin{array}{l}\text { Prestige, } \\
\text { scientific co- } \\
\text { operation }\end{array}$ & $\begin{array}{l}\text { Linear model } \\
\text { (science push) }\end{array}$ & $\begin{array}{l}\text { Choices re. 'big } \\
\text { science' }\end{array}$ & Basic \\
\hline $\begin{array}{l}1970- \\
1985\end{array}$ & $\begin{array}{l}\text { Science as a } \\
\text { problem } \\
\text { solver }\end{array}$ & $\begin{array}{l}\text { Industrial } \\
\text { competitiveness }\end{array}$ & $\begin{array}{l}\text { Linear model } \\
\text { (demand pull) }\end{array}$ & $\begin{array}{l}\text { Economic growth } \\
\text { and competitiveness }\end{array}$ & Applied \\
\hline 1985- & $\begin{array}{l}\text { Science a } \\
\text { source of } \\
\text { strategic } \\
\text { opportunity }\end{array}$ & $\begin{array}{l}\text { Managing inter- } \\
\text { dependence }\end{array}$ & $\begin{array}{l}\text { Complex model: } \\
\text { diversity of } \\
\text { institutions/ } \\
\text { processes }\end{array}$ & $\begin{array}{l}\text { Strategic } \\
\text { opportunities; long- } \\
\text { term needs incl. } \\
\text { science base }\end{array}$ & $\begin{array}{l}\text { Strategic/ } \\
\text { Mode } 2\end{array}$ \\
\hline
\end{tabular}

Ruivo's analysis is borne out by studies within other contexts. In their influential publication, The new production of knowledge, Michael Gibbons and his co-authors (1994) argue that we are currently witnessing a global shift from what they term Mode I to Mode 2 forms of knowledge production. What they refer to as Mode I knowledge 
production includes relatively familiar forms of research. The most important features include the following:

$<$ Research problems originate and are solved within the traditional academic context

$<$ Knowledge is based in specific scientific disciplines

$<$ Knowledge is relatively homogeneous

$<$ Knowledge is practised within relatively hierarchical organisational structures, and

$<$ Knowledge has relatively standardised forms of quality control, such as peer group evaluation.

Compared to this, Mode 2 knowledge is produced in contexts of application, it is transdisciplinary knowledge, it is heterogeneous and organised in new and diverse ways, and it involves new forms of accountability and reflexivity as well as new forms of quality control.

What are some the implications of these shifts?

I) If shifts like these become sufficiently widespread, they must begin to have an impact on scientific institutions. Some institutions, such as universities, have already started to respond to this challenge by appointing new kinds of 'knowledge workers' - scientists who have an entrepreneurial spirit. Other universities have entered into new kinds of alliances and forms of collaboration with non-universities. It should be clear that these changes require a new look at existing institutional mechanisms as far as research management is concerned.

2) The authors describe a second consequence as "the social distribution of knowledge". The new forms of knowledge are produced by and disseminated to individuals and groups across the social spectrum. Mode 2 knowledge production is taking place within social contexts that are very different from traditional places of scientific investigation. It is especially in this context where new developments in electronic and telecommunication are of crucial importance. One could argue, with justification, that the new forms of knowledge are both contributory causes and outcomes of innovation.

3) It is a key aspect of Mode 2 knowledge that those who wish to use and consume knowledge also have to become participants in the production process. Gibbons et al (1994:15) give the following example:

The goals of participation are no longer simply to secure some national advantage, commercial or otherwise. Indeed, the very notion of what constitutes an economic benefit, and for whom, is at the root of many debates not only in environmental science but in biotechnology and the medical sciences as well. For example, the current push towards "clean" technologies is about more than just economic benefit. It is also about stabilising collapsing ecological systems, the health and well-being of populations as well as commercial gain.

4) The new form of knowledge production is posing new challenges to governments and the way in which science policy is managed at a national level. It is specifically 
because of the socially distributed nature of Mode 2 knowledge that we witness two specific challenges: on the one hand, governments have to learn the (new) ability to participate in knowledge production wherever it takes place in the world; on the other hand, it also requires of them that they appropriate such knowledge within the national system of innovation. We are increasingly experiencing that transnational institutions are taking the lead in global knowledge production.

The shifts in R\&D described above have led to a revision of our understanding of the relationship between science and society. The old 'republic of science' ideal has given way to notions of 'strategic science', 'relevant science' and 'useful science'. This development can be ascribed to a number of factors operating within both industry and the higher education sector.

\subsection{Developments in higher education}

Various recent studies have claimed that the higher education sector worldwide is undergoing fundamental changes. These transformations are spearheaded by three important developments.

First, the higher education sector is the recipient of smaller and smaller government contributions (Etzkowitz et al 2000:4I; Jacob 2000:12-3; Etzkowitz \& Webster 1998:36; Sadlak 1992:1 14). Jacob (2000:12) remarks that it is important to emphasise here that it is not that science is receiving less funding per se, but that transdisciplinary applicationoriented research is being funded at the expense of discipline-based internally-driven science. This re-orientation is closely reflected in changes marking the research funding system which now very strongly urges user, stakeholder and beneficiary involvement in higher education research (Jacob 2000:13). Such involvement, which brings academic research closer to the context of application, is also likely to bring the academic community into contact with other centres of research excellence outside its own boundaries where it may be able to exploit advanced equipment and technology otherwise not available. In this sense, involvement that stretches beyond the boundaries of the academic environment is likely to provide an invaluable set of conduits for the circulation of knowledge and technology (Shove 2000:67; Etzkowitz et al 1998:I0; Balázs 1996:24; Martino 1996:3 18; Sadlak 1992: I I4; Tolbert 1985:46).

Second, these developments have been accompanied by increasing demands for greater accountability in the higher education research sector. Such accountability stands to be enhanced through closer collaboration with industry as this is bound to heighten the academic community's 'real-world' exposure to and awareness of those questions and trends that currently mark the corporate environment. The academic community is then in a better position to adjust its educational objectives and research directions in correspondence with the actual needs of industry (OECD 2000:4-5; Shove 2000:67; OECD 1996:25; Sadlak 1992: I I4; Tolbert 1985:46).

Third, the transformation within the higher education sector has been further augmented by an important change in the regulatory infrastructure governing the ownership of knowledge and, in particular, of research results. This change was introduced by the 
Bayh-Dole Act, formally known as the Patent and Trademark Amendments Act that was passed in 1980 in the United States. This Act assigns ownership of knowledge to the academic institution in which the discovery is made, even if the government has supported the research financially. The purpose of this legislation was clearly to speed up the transfer of technological knowledge from higher education to industry by eliminating certain governmental restrictions. In the process, it placed the responsibility for technology transfer firmly in the hands of the academic institution itself (cf. Etzkowitz \& Stevens 1998:223-5).

Thus, in terms of the Bayh-Dole Act, the higher education community is able to - indeed obliged to - benefit directly from the products of its research activity. This means that where higher education joins industry in a collaborative research project, the results of such a project represent a new source of revenue for the higher education institution. It may exploit this source through consultation or in the form of patent ownership, production activities, copyrights, and intellectual property rights. Through each of these means, the higher education sector becomes able to generate its own income. In this sense, the active transfer of usable knowledge and technology to industry contributes to greater internal budgetary flexibility (Sadlak 1992: I I4; Tolbert 1985:46).

\subsection{Developments in industry}

Etzkowitz and Webster (1998:36) suggest that closer linkage between industry and higher education represents, at least in part, the logical outcome of certain critical economic and structural developments. The most important of these, they suggest, is recognition of the economic importance of innovation, which, in turn, stimulates the development of complex technology.

The complexity involved in the development of the technology desired by industry reduces the likelihood that all the necessary capabilities will be found in-house. Tolbert (1985:46) adds that it is simply "not possible for one industry to cover all fields" which may impact on its technology, nor for it to "maintain internal exploratory programs in all areas of potential opportunity". Yet, it is possible for individual in-house scientists to work collaboratively with their academic associates to "gain early insight into the significance of basic observations over a broad range of technologies" (ibid). Such early insight is indeed regarded as vital in maintaining a competitive edge (Martino 1996:3 18; Salter et al 2000:32-3; Tolbert 1985:46). In addition, within this context of collaboration, industry can "enjoy the advice of leaders in many fields and have access to a variety of inter-related research-support systems" (Scott et al 200 I:I7). In this way, industry is then able not only to monitor the latest developments in its field, but also to enjoy access to the high-level expertise, technical capability and problem-solving capacity imperative to the stimulation of sustained innovation (Balázs 1996:24-5; Salter et al 2000:63-5).

In addition to the persistent monitoring of technological development and access to highlevel know-how, industry may also be inspired to collaborate with the higher education community by the growing cost of high-quality research in advanced technology. This increase can in part be ascribed to the avid efforts of academic scientists to commercialise their own knowledge products. This has made access to coveted knowledge and technology not only more difficult but also much more expensive (Jacob 2000:14). 
Jacob (2000:14) as well as Leydesdorff and Etzkowitz (1998:7), for instance, point to changes in leading corporations such as IBM, which has traditionally maintained large in-house R\&D concerns. In light of increasing technological complexity and the financial outlay it demands, such corporations have recently begun to supplement and in some cases even replace in-house R\&D with research agreements involving higher education partners. By so leveraging external R\&D sources, the corporation is in a better position to meet certain business needs faster, more cheaply, and, in many cases, with better technology.

The sheer complexity involved in the development of innovative technology as well as the fact that such development should occur at a rapid pace offers still one last rationale for closer collaboration between industry and higher education: access to a pool of experienced candidates for job recruitment. Martino (1996:3 I7-8) explains that those students involved in higher education research projects provide a rich source of potential employees to the industrial partner. These candidates already have experience in the technology desired by the industrial partner and may even have worked on one of its project. Thus, through collaborative interaction, industry actively shapes the direction of higher education research and so places itself in a position from which to select high potential future employees already equipped with the desired knowledge and experience. Once appointed, these candidates will, of course, also raise the level of expertise within the given corporation.

To summarise: The developments described above identify a number of factors that push and pull the higher education and corporate communities to engage in closer cooperation. When taken together, they point toward the beginnings of a new 'social contract' between science and society. This 'contract' requires that government support for academic research will be sustained (albeit at lower levels) as long as such research directly involves its users in order to guarantee relevance within the new knowledge-intensive global economy. What lies at the heart of this transition, of this new contract, is not merely the capitalisation of knowledge into an economic good but also new forms of R\&D collaboration.

Our discussion in this section has focused on recent and current shifts in modes of knowledge production. We have devoted much attention to a discussion of these shifts within academia and industry and on the resultant closer collaboration between these two sectors.'

Chapter four considers the form and nature of research utilisation across selected science domains.

I This focus on academia and industry is justified given that they together constitute about $60 \%$ of all R\&D produced in South Africa (cf. NACl: S\&T Facts and Figures 2002). 
The aim of this chapter is to illustrate how knowledge or research utilisation is 'manifested' in different domains of science. Four domains of science have been selected to illustrate the wide range of conceptions and models of research utilisation:

$<$ Agriculture and agricultural extension services

$<$ Applied social science and social policy

$<$ Health science and the health practitioner model

$<$ Engineering science and technology transfer.

\subsection{Agricultural extension services}

\section{Early agricultural extension}

The evolution of agricultural extension spans almost four thousand years, with the earliest evidence of the "dissemination of relevant information and advice to farmers" in Mesopotamia around 1800 BC (Jones \& Garforth 1997:2). Similar evidence has been discovered in early Egyptian, Roman, Greek, Phoenician and Chinese civilisations. Developments over the centuries, and in different parts of the world, laid the foundation for modern-day agricultural extension. An example is the emergence of agricultural texts during the Renaissance in Europe, subsequent to the invention of movable type around 1450, which served to disseminate the information translated from "old Latin texts or on the collected wisdom of farmers and their families" (Jones \& Garforth 1997:3).

An important innovation in the early 1800 s was the introduction of itinerant agriculturalists "who could meet farmers in their home localities, give instructional talks and demonstrations, advocate superior or new practices, and have discussions with the farmers" (Jones \& Garforth 1997:5). Similar arrangements were soon introduced in other countries such as France and Germany and migratory agriculturalists is still a feature of agricultural extension today.

\section{The emergence of modern agricultural extension}

According to Jones \& Garforth (1997:5), the first modern form of agricultural extension emerged during the potato famine in Europe in 1845. The Earl of Clarendon sent a directive to the Royal Agricultural Improvement Society of Ireland "to appoint itinerant lecturers to travel around the most distressed districts to inform and show small farmers, in simple terms, how to improve their cultivation and how to grow nutritious root crops other than potatoes" (Jones \& Garforth 1997:5). This more institutionalised form of agricultural extension - largely publicly- but also privately-funded - spread to other regions in Europe, and particularly Germany, which later became the model for other countries (Jones \& Garforth 1997:6).

In the United States, two developments after 1850 gave substantial form and shape to agricultural extension in that country (Jones \& Garforth 1997:7). The first was the emergence of the farmers' institute movement that was later to "become a national 
institution with federal support and supervision" (ibid). The second was the Morrill Act of 1862. Through the Act, the northern states were allocated pieces of land that they were to sell or use "for profit and the proceeds used to establish at least one college - hence, land grant colleges - that would teach agriculture and the mechanical arts" (National Research Center 1995:I). The land grant colleges were intended to bring a liberal, practical education to the working classes that would have "direct relevance to their daily lives" (NASULGC 1999).

Teaching was the first function assigned to the land grant colleges. Two other core functions were to develop over time. In the late 1880 s, a research function was introduced "which recognized the need for original research to underpin the teaching of agriculture and help develop agricultural innovations" (National Research Center 1995:8). The dissemination of research findings to farmers was organised through the establishment of agricultural experiment stations at each of the land grant universities on the basis of the Hatch Act in 1887 (Jones \& Garforth 1997:7; NASULGC 1999).

This system of dissemination was later enhanced with the introduction of 'extension' as the third function of the colleges (National Research Center 1995:8). This was brought about via the 1914 Smith-Lever Act, which provided for the creation of Cooperative Extension Services associated with each land grant institution (NASULGC 1999). These Services were co-ordinated jointly by the federal, state and local county governments (Jones \& Garforth 1997:8; National Research Center 1995:8).

\section{Agricultural extension in South Africa}

At the time of the Smith-Level Act in the US, state agricultural extension in South Africa was still in its nascent state. The first official agricultural extension service was established in 1925 in the newly formed Division for Agricultural Education and Extension in the Department of Agriculture (Penzhorn 1987:12).

In the fifteen years prior to this (after the formation of the Union in 1910), the predominant form of extension work was the provision of advice to farmers based on research conducted at institutions such as Onderstepoort and the agricultural colleges such as Elsenburg, Cedara and Potchefstroom (Saaiman 1998:52). This information was gleaned from publications, the exchange of letters, and advice obtained during visits to these institutions. It was up to the farmers themselves to interpret and apply the information that was brought to their attention.

According to Saaiman (1998:52), three factors led to the establishment of agricultural extension services in South Africa. The first was the appearance of a report in the early 1920s by a Colonel Heindrich du Toit, which drew attention to the dangers of water and wind erosion. Secondly, Colonel du Toit, who had heard about the land grant colleges and extension services in the United States, advocated the establishment of a separate extension service in this country. Thirdly, the introduction of the Department of Agriculture's 'demonstration train' served as an important form of publicity to the farmers of the newly established extension services. 
In 1925, there were only six extension officers who were stationed in Natal, the Free State, the Transvaal and the Cape Colony (Penzhorn 1987:12). They were closely linked to the agricultural colleges from which they could obtain the information they needed to carry out their services. By the 1930s, the number of extension officers had been increased to about 20, largely because of demands from farmers for the service to be offered in their area (Saaiman 1998:53).

Initially, neither the senior Departmental officials nor the extension officers were clear about how these services were to be carried out. According to Penzhorn (1987:12), the extension officers were very enthusiastic, however, in the hope that by passing on what they had learned about agriculture at university, they would help to change and improve on the old-fashioned agricultural practices of the time. They did this via farm visits, meetings in the extension offices, the exchange of letters, and occasionally some form of instruction at 'farmer days' or farmer association meetings (Penzhorn 1987:12). The extension officers were involved in, amongst others, approving the construction of barns, silos, housing, stables and dams, grading cattle, sheep and chickens, and providing advice about seeds, soil, poultry, disease and pests (Penzhorn 1987:I2; Saaiman 1998:53). The extension workers were also instrumental in helping farmers to get better organised through farmer associations and shows (Penzhorn 1987:12).

In the 1930s, 'co-operative demonstrations' were introduced as a method of extension work, based on the idea that "seeing is believing" (Penzhorn 1987: I2; Saaiman 1998:53). Amongst others, extensionists demonstrated improved fertiliser practices, and the benefits of a new imported grass which was aimed at helping farmers to overcome their grazing problems and to prevent water and wind erosion (Penzhorn 1987:12). While these co-operative demonstrations were very popular and successful in the 1930s (Penzhorn 1987:13), it was soon realised that they were inadequate insofar as they focused on single farm activities rather than on the farm as a whole system (Saaiman 1998:54).

This gave rise to a new phase in agricultural extension in the 1940s known as 'whole farm planning' after the promulgation of the Land Conservation Act in 1946 (Penzhorn 1987:13; Saaiman 1998:54). One of the primary motivations for this approach was based on the finding in agricultural science that erosion could best be dealt with by covering land that was vulnerable to erosion with natural veld, and by implementing a crop rotation system (Penzhorn 1987:14). The extensionists needed to demonstrate these strategies over a period of time to convince the farmers that they worked.

During the 1940s, a number of other problems led to further changes in agricultural extension. For instance, it had become apparent that the scientific assistance and advice available to extension officers from the Pretoria Head Office was inadequate. This ushered in the phase of decentralisation in agricultural extension services (Penzhorn 1987:14). This began in 1945 with the establishment of a Division for Land Conservation and Extension which effectively brought the extension workers into closer contact with researchers and agricultural engineers, reducing their sense of isolation (Penzhorn 1987:15).

However, the lack of promotion opportunities still plagued the extension officers. As part of the decentralisation process, in 1946 the Department divided the country into five 
districts with headquarters in Pretoria, Bloemfontein, Pietermaritzburg, Queenstown and Stellenbosch (Saaiman 1998:54). This was later extended to seven districts and, by 1957, there were no less than 206 extension posts (ibid) to which extensionists could aspire for promotion (Penzhorn 1987:15). The general work performance of the extension officers also improved since they could now work as a team (instead of as individuals) addressing problems and needs within their districts.

Another issue had to do with the lack of formal, specialised education and training in extension. Up until the late 1940s, extension officers gathered once a year for courses in their area of speciality, offered by lecturers and researchers at the agricultural colleges (Penzhorn 1987:14), but there were no specialised courses for extension work itself. Extensionists began to demand education and training in agricultural science, as well as in methods of teaching and working with adults. The struggle for the introduction of university-level education began during these years but it was only in 1958 that a Department of Agricultural Extension was established at the University of Pretoria, which offered postgraduate degrees in agricultural extension (Penzhorn 1987: 16; Saaiman 1998:54).

Some years after the decentralisation of the extension services, the Department underwent another major reorganisation, with the result that the districts were jointly responsible for extension, teaching, research and conservation (Penzhorn 1987:16). At the same time, a number of specialised research institutes were established and, where available, extension services were coupled with faculties of agriculture in the district. This led to closer co-operation between research and extension in the districts, which, it was hoped, would make it easier for research results and technologies to find their way to the farmers, and for new ideas and discoveries to reach the researchers. However, this interaction between research and extension still depended largely on the efforts and interest of individual extension workers and researchers.

In 1968 a report of the Interdepartmental Study Committee for the Use of Agricultural Land gave rise to a whole new approach to extension work (Saaiman 1998:54-55). The report emphasised the importance of 'optimal resource utilisation', which shifted the mandate of the extension services from land conservation to the introduction of farming systems that would bring about a more balanced and integrated approach to the utilisation of resources.

As time passed, farming became more specialised and there were calls for greater specialisation among the extension workers, a closer working relationship between them and the researchers, and decentralisation of extension services. This led to the establishment of the first agricultural development centre on the Outeniqua experimental farm in 1989 where a team of specialists from across the disciplines focused their attentions on the specific problems of the region (Saaiman 1998:55). Ongoing research, extension work and short courses were now located under one roof, working together to bring about sustainable and integrated farming systems.

Up until 1993, the agricultural function at national level was divided between three agricultural departments, namely the Department of Agriculture, the Department of 
Agricultural Development, and the Department of Local Government, Housing and Agriculture. On the ${ }^{\text {st }}$ of April 1993, all these functions were grouped together in a new Department of Agriculture (Saaiman 1998:55). In the context of the new South Africa, the issue of small-scale farming was brought onto the political agenda and in 1993, a division for small farmer development was introduced in the Department. The focus of extension work shifted again, this time to small-scale farming as well as assistance in the Land Reform programme (Saaiman 1998:55).

\section{Models of agricultural extension}

\section{Linear models of agricultural extension}

With the growth of agricultural sciences, a range of agricultural technologies have been developed "outside the actual farming sector by public sector research organizations" and, more recently, private sector companies in the industrialised world for whom agricultural R\&D is very profitable (Nagel 1997:2). For many years, the use of this agricultural technology and knowledge was facilitated by the 'researcher-extension-farmer linkage' in a simple linear model of technology transfer (ibid). In this model, the emphasis is on 'extending' the results of agricultural research to farmers by giving advice, disseminating information, and transferring new agricultural technologies through the person of the extension officer (SA Institute for Agricultural Extension 2002). According to Coutts (1995:18), the technology transfer model "implies a predetermined technical or managerial improvement where extension has the task of 'increasing the rate of adoption'."

Another linear model, developed by a group of rural sociologists in the late 1930s, outlined five stages in the diffusion and adoption of agricultural innovations (Berggren 200I:9). This model, known as the 'five phase resource linkage model' (Stetler 1985:I) included the stages of awareness, information, application, trial, and adoption (Berggren 200I:9). Rogers (1983) later refined this framework in his 'diffusion of innovation' model, which could be utilised to investigate the use/application of research findings (Berggren 200I:10). Rogers' stages in this innovation-decision process included knowledge, persuasion, decision, implementation, and confirmation (ibid).

\section{'Human development' models of agricultural extension}

In modern times, agricultural extension services have expanded and diversified - both in terms of the content of and approach to the service, and in the organisational forms established to carry out these activities (Jones \& Garforth 1997:10). These shifts are underpinned by new emphases in agriculture internationally, such as integration, sustainability and the involvement and development of rural communities.

The somewhat simplistic linear models of extension work have therefore come under fire in recent years. In the first place, they do not take into account the wealth of knowledge, information and expertise within the farming community itself, since they were based on the 'superior' agricultural sciences (Nagel 1997:2). Newer approaches incorporate "the clients' own knowledge and ingenuity, individually and collectively, ... as a major resource; solutions to local problems are to be developed in partnership between agent and clients" (Jones \& Garforth 1997: I I). 
Secondly, the linear models are unable to deal with the increasingly complex nature of agricultural technology and the circumstances within which farmers operate (Nagel 1997:2). This gave rise to the broader approach of human resource development, which emphasises equipping rural farmers - men and women - with the basic skills required for identifying problems and evaluating possible options (Nagel 1997:2). In some cases this has extended to teaching numeracy and literacy, as well as vocational, "managerial and organizational skills that will enable farmers to increasingly solve their own problems" (Nagel 1997:3). According to Coutts (1995:18), the human development approach "implies that given the right conditions, information, mutual interaction and opportunity, people can develop solutions to their problems and take steps to improve the situation. Extension's role then, is to facilitate such interaction."

These developments are reflected in agricultural extension in South Africa today. State agricultural extension services go far beyond the provision of advice and information to farmers. By way of example, the aims and objectives of agricultural extension in the Western Cape Department of Agriculture (WCDA 2002) are provided in box I.

Box I: $\quad$ Aims and objectives of agricultural extension in the Western Cape Department of Agriculture

"The aim of our Extension Services is to promote sustainable agricultural systems within the Western Cape in order to ensure prosperous farming communities and rural livelihoods.

Our objectives include:

- To identify and prioritise agricultural development problems in conjunction with farming communities

- To transfer proven and applicable agricultural technology and information to farming communities on an ongoing basis.

- To evaluate and demonstrate proven agricultural technology under local conditions with farming communities.

- To identify production, development and marketing opportunities for farming communities.

- To engage in capacity building and organisational development within mostly developing farming communities.

- To promote cooperation and coordination with other stakeholders within the development sphere."

Source: WCDA (2002)

As elsewhere in the world today, agricultural extension officers in South Africa are not only employed by government. Increasingly, other sectors - such as the agricultural chemical and fertiliser industry, agricultural co-operatives, and non-governmental organisations involved in rural development, draw on their expertise (WCDA 2002). They can also act as private consultants.

Support for agricultural extension is also provided by a range of non-governmental organisations and research institutes across the country. An example is the Centre for Low Input Agricultural Research and Development (CLIARD) based in KwaZulu-Natal. 
The aim of the organisation is "to develop the organisational and individual capacity of rural people around sustainable farming methods, research on specific crops and problem solving with farmers" (Sangonet 2002). The organisation also provides training for agricultural extension officers, agricultural assistants and farmers.

The field of agricultural extension as an area of specialisation has also continued to grow in South Africa and around the world. Many universities offer postgraduate qualifications in the field and journals dealing with agricultural extension have been introduced (for example, the South African Journal of Agricultural Extension, and the Journal of Agricultural Education and Extension in Europe).

\subsection{The applied social sciences and social policy}

The domain of social research is the social world; its focus is on understanding societies and cultures, and the actions and interactions between the individuals within them. As such, contemporary social science research has real and potential application in the crosssection of social sectors (government, non-governmental and community-based organisations, and commerce and industry) and domains (health, education, business, etc). It can inform policy-making, and contribute to the conceptualisation, development, implementation and evaluation of social interventions, processes and practices. It can serve to solve specific social problems, or to broaden the social knowledge base of those who engage with it. Given the close relationship between social inquiry and the world it impacts on, it is not surprising that reflections on the application and utilisation of social knowledge have been around for some time.

\section{Early models of the utilisation of social research in policy-making}

According to Bulmer (1982:I), social research has influenced the policy-making process ever since the emergence of "adequate scientific methods for social inquiry" in the nineteenth century. Variously referred to as 'positivism', 'empiricism' or 'behaviourism', amongst others, this early approach to social inquiry drew on the logic and methods of the natural sciences (Hughes 1990:19). As such, it involved the empirical observation of social 'facts' and the discovery of social 'laws' that governed these social phenomena. The successes of the natural sciences in the nineteenth century led to considerable confidence in the methods and the logic of inquiry in these fields - a confidence that was extended to the methods of the emerging social sciences. In particular, the objective and scientific nature of these methods was seen as the only way to overcome the weaknesses of the policy-making process (Bulmer 1982:33):

The predominant tone was to stress the practical usefulness of research, its essentially commonsensical and empiricist character, and to strike a note of optimism that research would be a means of overcoming the 'ignorance' and 'prejudice' of politicians and administrators.

Nilsson \& Sunesson (1993:366-367) describe this as 'scientification' - "the replacement of ideology and political reasoning with science". The different ways in which the social sciences developed in the United Kingdom and the United States gave rise to slightly different approaches to the use of social research to inform the policy-making process. 


\section{The 'decisionist' model}

In the nineteenth century in the United Kingdom, when social research was largely empiricist in nature, the relationship between research and policy-making took on a specific form which Martin Bulmer refers to as the 'empiricist' model of knowledge us (Bulmer 1982:33). Bulmer (1982:31) defines 'empiricist' in this context as "a view of empirical social inquiry which holds that such inquiry is primarily factual in nature and that the task of social research is to produce 'facts', ... [which] when fed into the policymaking process, will enable policy-makers ... to reach the best decisions on the basis of the information available." The following diagram depicts the relationship between social research and policy-making in the 'empiricist' model (Bulmer 1982:31):

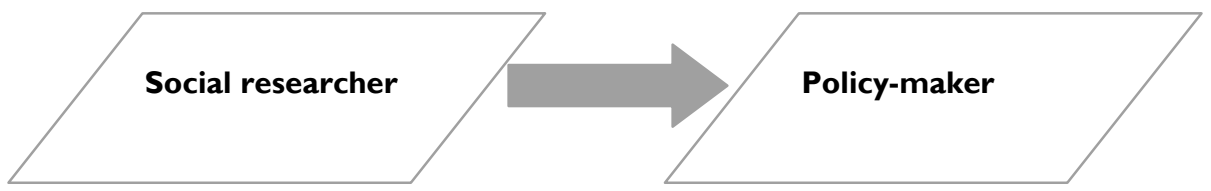

Although the term 'empiricism' captures one aspect of the nature of knowledge use in this model (the presumed separation of 'facts' and 'values', Jürgen Habermas proposed that this model is called the 'decisionist' model - a convention followed here. ${ }^{2}$

A number of social inquiries of this kind were undertaken in the nineteenth century - by political activists or wealthy individuals for whom social inquiry was a worthwhile pastime, or were commissioned by governments (for example, the British Royal and the American Presidential Commissions) (Bulmer 1982:21,32). According to Bulmer (1982: I-2), the earliest example of a government-commissioned inquiry in the UK, the results of which were to inform policy-making and social reform, was the Royal Commission on the Poor Law in 1834. The investigation involved gathering 'facts' from the Poor Law authorities in order to "review the workings of the Elizabethan Poor Law and to make recommendations to the government for its reform" (Bulmer 1982:2).

This tradition continued with, for example, Chadwick's 1842 study into the sanitary conditions of the 'labouring population', the work of the statistical societies in the nineteenth century, Mayhew's journalistic writings about the working class and the poor in London in the early 1860s, and Charles Booth's extensive study of poverty in the 1880s (Bulmer 1982:3-14). It is important to note that while these researchers had specific intended users in mind (policy-makers) and the intention to bring about social reform, it was they who chose what to investigate and how: the researcher collected facts about a social phenomenon or a group of people (such as those living in poverty) and, by publishing these facts, alerted politicians to the existence of these social problems. It was assumed that this would influence future policy decisions and actions.

2 There are two reasons why we prefer the term 'decisionist'. First, the word 'empiricism' is usually associated with a certain epistemology or theory of knowledge that emphasizes empirical data and methods of inquiry. To also use it to describe a certain model of knowledge use may be confusing. Second, the term 'decisionist' focuses more on the way in which knowledge is applied and used within this model, i.e. as the (factual) basis for political and social decision-making. 
While the decisionist tradition has been widely criticised and subsequently adapted or abandoned, this form of social research utilisation is still evident in the activities of government statistical services around the world today.

\section{The 'engineering' model}

Where British social inquiry emphasised the gathering of social facts, other social science traditions (such as that which developed in the US) gave additional emphasis to the explanatory role of social science theory (Bulmer 1982:37-38). In other words, theoretical ideas and hypotheses were brought to bear on the empirical data. In what has come to be termed the 'engineering' model of social research utilisation, the relationship between social research and policy-making is rooted in the positivist assumptions about the former, and the conceptions of the latter as being inherently rational (Albæk 1995:80):

A clear symmetry exists between rational decision-making and positivist science. In rational policy making 'policies are hypotheses' ... hypotheses of how means (i.e., given social programs) will lead to desired ends. This process resembles the classical scientific experiment: hypothesis intervention - effect.

Modelled on the problem-solving approach in engineering, the engineer is the role model for the social researcher who, as a technician or social engineer, "commands the knowledge to make the necessary investigation and interpret the results" in order to solve a social problem (Bulmer 1982:42). In this role, the social researcher engages in applied research, that is, the application of existing theoretical knowledge to the problem at hand (Bulmer 1982:43). Bulmer (1982:42-43) describes the engineering model as follows:

The model is a linear one. A problem exists; information or understanding is lacking either to generate a solution to the problem or to select among alternative solutions; research provides the missing knowledge; and a solution is reached. Typically a single study will be involved. This - with its data, analysis and conclusions - will affect the choices that decision-makers face. Implicit in such an approach is agreement upon ends. It is assumed that policy-makers and researchers agree upon what the desired end-state should be. The role of research is to help in the identification and selection of appropriate means to reach that goal ...

The following diagram depicts the relationship between social research and policy making in the engineering model (Bulmer 1982:43):

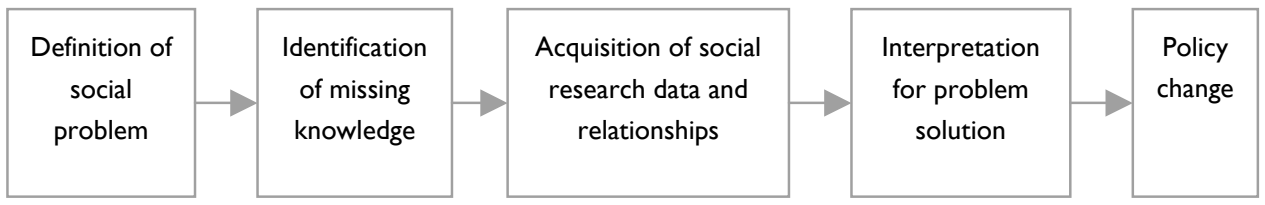

So confident were social researchers and policy-makers alike that this approach to applied research would make a positive impact on the policy process, that it became the dominant model in American public administration in the 1960s and 1970s (Albæk 1995:8I). According to Albæk (1995:92), "rational decision-making and policy making, problem-solving, etc. were made more or less synonymous with applied social science in 
the form of policy analysis, evaluation research, cost-benefit analysis or whatever label was attached to it."

The engineering model came into widespread usage in the UK because of the influential Rothschild Report of 197I, which made a clear distinction between basic and applied research (Bulmer 1982:43). Rothschild proposed that applied social research conducted for government should take place on a customer/client basis - what we today would refer to as contract research, "a role for research [that] was taken from technology" (ibid).

In the engineering model, the intended users and their specific needs for research are clear: the demand arises from within political circles around a social problem that needs solving; this is achieved through generating useful and relevant scientific knowledge which is then utilised by policy-makers in order to make a decision.

\section{Critique of earlier models and the emergence of new ideas}

The emphasis on utilising social research for policy-making soon gave rise to investigations of utilisation itself. In particular, three empirical studies conducted in the late 1970s and early 1980s (Caplan 1976, Knorr 1977, and Weiss with Buchavalas c1980) indicated that social research was seldom used, and that when it was used, it was seldom used in the ways anticipated by the engineering model (Bulmer 1982:48; Neilson 200I:9). According to Albæk (1995:82):

Just a few years after evaluation and policy research took the American corridors of power and administration by storm, it became depressingly clear that one could only rarely and with difficulty prove that research had exerted any specific influence or had any beneficial effect on the policy that was implemented.

Observers at the time theorised about why policy makers were not making use of research. Caplan (1979), for example, in his 'two communities' theory ascribed the nonuse of social research to the vastly different worldviews of researchers and policy-makers (Neilson 200I:4). Others suggested that non-use was the result of a misconception on the part of both parties (policy makers and researchers) as to the nature of the processes involved (Albæk 1995:82; Bulmer 1982:45). According to Bulmer (1982:45), for example, a common problem with the engineering model is that it

... misunderstands the policy-making process, fails to take account of the complex processes by which decisions are reached, exaggerates the role of the 'decision-maker' for whom research is carried out and gives unwarranted authority to the research input which the policy researcher provides. The results of policy research lack the degree of conclusiveness which their practitioners claim, either as scientific knowledge or as confirmation of ordinary knowledge.

In other words, as understandings about what social research can viably offer in terms of concrete explanations or solutions, and observations about the policy-making process shifted (that it is not entirely rational, and is messy and confusing), so too did conceptions of the ways in which social research can be utilised in policy-making. 
The 'enlightenment function' of social research

The findings from the two studies referred to (Weiss, and Knorr) gave rise to a different explanation of the use or non-use of social research in policymaking and new ideas about the ways in which research was actually utilised.

In 1978, Carol Weiss (1978:22) wrote that

The prevailing concept of research utilization is one that stresses application of specific research conclusions to specific decisional choices. ... It is the series of linkages, from problem definition to policy choice, that marks the 'use' of research. ... However, the major use of social research in public policy making may not be problem solving. It is beginning to look as though research use is a much more diffuse and circuitous process.

Weiss labelled this more diffuse type of use as the 'enlightenment function' of social research. In this respect (Neilson 2001:9, quoting Weiss 1977),

... government decision makers tend to use research indirectly, as a source of ideas, information, and orientations to the world. Although the process is not easily discernible, over time it may have profound effects on policy. Even research that challenges current values and political feasibilities is judged useful by decision makers.

Weiss went even further in unpacking the various possible 'uses' of social research, of which the enlightenment function is only one. These are listed in the box 2.

\section{Box 2: Weiss's seven meanings of 'use'}

- Knowledge-driven: application of basic research; this model assumes that basic research provides an opportunity for policy-relevant research which can then be applied;

- Problem-solving: communication of research on an agreed upon problem to the policy maker; this model implies that there is consensus between the researchers and the policy makers on the solution or end-state;

- Enlightenment: education of the policy maker; that with time the accumulation of research will influence policy by educating the policy maker;

- Political: rationalization of previously arrived at decision; used by policy makers to bolster support or provide ammunition for opposition;

- Tactical: requesting additional information to delay action; often used by government agencies or other organizations/institutions as a response to a problem or issue;

- Interactive: competing information sources; this implies that policy makers are actively searching for policy-relevant information that is not based on social science research; this type of use is considered to be more realistic of how policy makers use information in the policy process;

- Intellectual enterprise: policy research is just one type of many intellectual pursuits.

Source: Neilson (200I:9)

Another important finding of these empirical studies was that the term 'research' can also take on various meanings, each of which has implications for the nature of research 
utilisation. Weiss (1991) identified three models or hypotheses of research which, she suggests, "underlie the use of research by policy makers as well as others such as interest groups, and each hypothesis of use makes its own assumptions about the nature of the policymaking process" (Neilson 200I:I0-II). The three models of research include research as data, as ideas, and as argumentation. These are described in box 3 .

Box 3: $\quad$ Weiss' three models of research

- Research as data: likely to be influential in situations of consensus on values and goals; when two or three alternatives are sharply opposed; and when decision makers are analytically sophisticated;

- Research as ideas: likely to be influential at the early stages of policy discussion; when existing policy is in disarray; when uncertainty is high; and in decentralized policy arenas when many separate bodies decide;

- Research as argumentation: likely to be influential when conflict is high; in legislatures; and after decisions have already been made.

Source: Neilson (200I:II)

In a study conducted by Karin Knorr (1977) around government officials' use of research (Weiss 1978:25-26), similar conclusions were reached:

... utilization does not follow the pattern of technical implementation of results established in the natural or technological sciences. Rather, the main area of utilization consists of an indirect (bound to undergo further decision processes), diffuse (taken into account to various degrees and at different positions), difficult to localize utilization responsibility (distributed over various decision levels) and possibly delayed discursive processing of the results in the stage of program development and decision preparation. The low visibility of this kind of utilization and the far too high expectations contribute to the popularity of the thesis that little utilization takes place. Its plausibility should be re-examined in the light of the present data and arguments.

In summary, the enlightenment function of social research is about broadening policy-makers' knowledge bases (Neilson 200I:I0) and "intellectual background of concepts, orientations and empirical generalisations" (Bulmer 1982:48). This gives them new ideas and perspectives on the issues at hand in order to "formulate problems and to set the agenda for future policy actions" (Bulmer 1982:48; original emphasis). The emphasis is on orientation rather than developing specific solutions. And research utilisation takes the form of "a gradual shift of conceptual thinking and, therefore, the policies which support that conceptual thinking” (Neilson 200I:I0).

\subsection{Utilisation of health sciences research for improving practice and bringing about organisational change}

In the field of nursing, our review of the literature reveals at least two ways in which research is used: to inform policy at the organisation/institution and system levels, or to improve practice on the ground. More broadly, according to Rutledge (1995:2), research 
utilisation can create the "basis for policy, procedure and protocol validation, improved patient outcomes, enhanced professional practice environment, and contained health care costs." Given the emphasis on the relationship between research and policy-making in the previous section, the focus in this section is on the utilisation of research to improve practice and bring about organisational change.

As with the use of social research (see Section 4.2), the utilisation of research in the field of nursing has been categorised as instrumental, conceptual or symbolic/persuasive. 'Instrumental' use implies the direct application of research findings to a specific problem. In the nursing context, this could include the production and implementation of "procedures, clinical protocols, practice guidelines, standard care plans, new techniques" (Berggren 200I:7), scoring systems or research-based policies (Rutledge 1995:4).

'Conceptual' use implies that research is used indirectly to broaden the individual's understanding and knowledge base and thereby "inform their practice in ways that are often indirect" (Berggren 1995:7). A third possible use of research in nursing practice is 'persuasive' use in which nurse practitioners draw on research findings to persuade others to adopt a new or improved practice or policy (Berggren 1995:8). According to Berggren (1995:7), most empirical studies of utilisation within the field of nursing have focused on the instrumental aspects.

\section{Models of research utilisation in nursing practice}

Research utilisation as a field of inquiry, and as an integral part of nursing practice, has received considerable attention and, since the 1970s, a range of models or frameworks for utilisation has been developed (Stetler 200I:272). These models "differ in their organizing frameworks and processes in terms of their target populations, structures, processes, and specific outcomes" (Beyea \& Nicoll 1997:I) and reflect shifts in emphasis in the underlying paradigms of nursing practice (Clarke 1995:I). Models of research utilisation in nursing were preceded by, and initially based on, studies of the diffusion of agricultural information and technology in the early part of the twentieth century. More recently, theories of organisational culture and decision-making have also informed the development of utilisation models in this field (Dobbins 1998:8).

Today, in addition to the more generic models for the nursing profession as a whole, a variety of specialty-based models have emerged (Beyea \& Nicoll 1997:2) which are aimed at improving practice in specific areas of nursing, such as oncology, perioperative and critical care nursing. It is beyond the scope of this review to consider all of these models. Instead, four models of research utilisation which have emerged over the past 30 years, and which, according to Stetler (1985), have been influential in the field, are considered.

All of these models focus on research utilisation as a means for diffusing innovations and bringing about planned change in nursing practice. However, each defines 'research' and 'utilisation' in slightly different ways: in some, research is taken to mean research findings or products, while in others, the methods and processes associated with research are also an integral facet of research utilisation. What is also interesting is that in some of these models, nurses are producers as well as users of research. In other words, the process of research utilisation involves the production of new knowledge and knowledge 
products (such as new protocols or guidelines for practice) and is thus essentially a form of action research.

\section{The Western Interstate Commission for Higher Education in Nursing (WICHEN) model}

One of the early influential models of research utilisation in nursing arose out of the WICHEN project conducted in the mid-1970s (Stetler 1985:I). Based on the 'five phase resource linkage' model in agricultural extension (see Section 4.I), the WICHEN model focused on the diffusion of innovation and planned changed. Nurses, in the role of organisational change agents, would "provide a link between research and practice. Through a support system of workshops and consultations, participant nurses were to utilize research findings (and concepts of planned change) to solve an identified practice problem" (Stetler 1985:I).

Although the emphasis in this model was on using research findings, in practice other sources of information were frequently drawn upon in the development of innovations. In addition, the use of research often took on the form of the production of research. An example is a project on grieving spouses conducted by Product and Breu in 1978, who adapted the research findings in order to develop a standardised nursing care plan. According to Stetler (1985:2), "In testing this plan, research utilisation was operationalised in a fashion almost indistinguishable from research production" in that experimental groups were used and statistical comparisons made, as well as reference made to, for example, 'investigators' and 'subjects' in the report.

\section{Conduct and Utilization of Research in Nursing (CURN) model}

In the late 1970s, the CURN project developed and tested a new model, which conceptualised research utilisation as an organisational process (EBCHP 2002). As with the WICHEN model, CURN focused on the diffusion of innovation and planned change. However, while the WICHEN model was based on the use of findings, the CURN model emphasised the use of research as both product and process to inform organisational development. The product was invariably a clinical protocol, and the process "a model for the implementation and evaluation of these research findings" (Stetler 1985:2). As such, research utilisation included a range of activities, starting with the identification and synthesis of relevant and trustworthy studies, the translation of this research knowledge into a clinical protocol, and finally, the implementation of the protocol in a practice setting.

\section{The work of King and colleagues}

In the early 1980s, King and others developed a model of research utilisation that focussed on the communication and dissemination of research findings, "directly from researchers to relevant practicing nurses" (Stetler 1985:2). Stetler (1985:2-3) characterises this model as an educational approach involving the following steps:

$<$ The recruitment "of specific nurse learners for whom the results would be applicable (e.g., educators and/or practitioners)." 
$<$ The translation of research findings into a format that could be easily understood by nurses, via interaction between the researcher and the nurse to ensure relevance to practice.

$<$ The dissemination of the results of this translation process via a range of educational strategies (for example, in a series of classes).

$<$ The "evaluation of the program's overall cost benefit as well as effectiveness of each of its components."

\section{The Stetler Model of Research Utilization to Facilitate Evidence-}

\section{Based Practice}

The Stetler Model has evolved over the past 25 years. In 1976, Stetler and Marram developed an individual practitioner-oriented model of research utilisation, which was "designed to bridge the gap between research and practice by directly involving the individual practitioner on a routine basis" (Stetler 1985:3). Stetler refined the model in 1994 and again in 200I (Stetler 200I:272,273).

This last development was essentially a response to the emergence of evidence-based practice (EBP) in nursing in the 1990s, which brought existing research utilisation models into question (Stetler 2001:272). According to the Evidence Based Health Care Project web site (EBHCP 2002), EBP "is the process by which nurses make clinical decisions using the best available research evidence, their clinical expertise and patient preferences. Three areas of research competence are: interpreting and using research, evaluating practice, and conducting research."

Research utilisation and EBP are not the same thing however. Rather, research utilisation provides a foundation of research and research-related action which, "when implemented and sustained," facilitates EBP (Stetler 200I:272-273,278). ${ }^{3}$ In addition, core features of both research utilisation in the Stetler model, and EBP in general, are critical thinking and reflective practice: they are effectively 'mindsets' in which "professional practice [is] enhanced by a culture of clinical scholarship” (Stetler 2001:272).

In the Stetler Model, research utilisation is conceived of as "the process of transforming research knowledge into practice" and involves the utilisation of research as both product (findings and validated measuring instruments) and process (Stetler 200 I:272). For Stetler (ibid), the use of "research-as-a-process refers to use of individual components of the research method for the purpose of routine problem-solving rather than for the conduct of research." Stetler (1985:3-4) also draws a distinction between the 'action' (direct / instrumental) and 'cognitive' (indirect/ conceptual) uses of research findings.

3 According to the Knowledge Utilization Studies in Practice web site (KUSP 2002), both "knowledge utilization and evidence-based practice are broader than research utilization, encompassing the use of forms of evidence other than research evidence alone." 
The 200 I version of the Stetler Model involves five phases in the research utilisation process. These include (Stetler 2001:7):

I) preparation

2) validation

3) comparative evaluation/decision-making

4) translation/application, and

5) evaluation.

This approach requires that nurses make judgements at each step of the way.

It must be noted that despite the existence of these and other models and frameworks for research utilisation, empirical evidence suggests that utilisation seldom occurs in practice (Dobbins 1998:47). In part this has to do with the observation that "bringing about research-based clinical change requires more than simply acquiring knowledge" (Dobbins 1998:46). In other words, dissemination alone is insufficient for utilisation to occur. Dobbins (1998:47) argue that research also has to be taken up in order for it to be used in policy or practice. This, in turn, implies that nurses require particular knowledge and a range of skills in order for effective utilisation to take place (Berggren $2001: 8)$. Such skills might include the ability to critically appraise existing research, make decisions, and assess whether a particular intervention would be appropriate in a particular setting.

This echoes the recent emphasis on the 'absorptive capacity' of industry in the process of utilisation; in other words, the skills required by users of research needed to translate, assimilate and apply information, knowledge and methods. In the words of Kitson et al (1996, quoted in Dobbins 1998:7): "Transforming research into practice is a demanding task requiring intellectual rigor and discipline as well as creativity, clinical judgment and skill, and organizational savvy and endurance."

\section{Institutionalisation of research utilisation in the health sciences}

The extent of the field of inquiry into knowledge utilisation in the health sciences is indicated by the range of formal organisations and resources dedicated to enhancing and facilitating the use of research to improve practice. These are particularly evident in North America and in some European countries, and range from Centres and Institutes which produce research and endeavour to support and facilitate research utilisation in practice, to web-based resources containing, amongst others, guidelines, published articles and empirical reports. Brief descriptions of a few of these are provided below.

\section{Centre for Knowledge Transfer, University of Alberta}

The health sciences at the University of Alberta in Canada have started two initiatives aimed at enhancing knowledge utilisation. One of these is the Centre for Knowledge Transfer which is an "interdisciplinary collaboration for the education of graduate students with a specific focus on knowledge utilization and policy implementation" (CKT 2002). The Centre's mission is "To increase research-based decision-making in Canadian healthcare settings" by conducting research around, and training graduates in, knowledge transfer, and "making opportunities available for students to collaborate with policy makers, managers and service providers as part of their educational preparation" (ibid). 
Knowledge Utilization Studies in Practice (KUSP), University of Alberta

The second initiative is a research programme known as Knowledge Utilization Studies in Practice (KUSP), the purpose of which is "to develop knowledge and research utilization theory that can be used to increase the use of research by nurses and other allied health professionals to improve patient and client health outcomes" (KUSP 2002). It also aims to build capacity and skills for modelling research utilisation processes.

The research program includes five areas of study:

I) determinants of research utilization studies

2) policy studies

3) synthesis studies

4) outcomes studies and

5) intervention studies.

All of these are based on philosophical, scientific and historical foundations.

The National Center for the Dissemination of Disability Research (NCDDR) In the field of disability research, the functions of the NCDDR are (NCDDR 2002):

I) to assist researchers from NIDRR4-funded research projects to increase the utilization of their research outcomes, and

2) to identify and test a range of dissemination strategies involving direct dissemination to a variety of audiences targeted by NIDRR grantees.

In order to achieve these goals, the NCDDR provides resources and networking opportunities to practitioners in the field. The activities of the Center include, amongst others, the production of guides and explanatory materials, and the training of NIDDR grantees, to improve the effective dissemination of their results; surveys of potential users and their needs; monitoring and evaluation of dissemination activities to assess their effectiveness; and, hosting a web site which serves as an extensive information source (NCDDR 2002).

\subsection{The utilisation of science and engineering research for technological development}

Our final section focuses on the utilisation of science and engineering research in the form of technological innovation. The Oslo Manual (OECD 199I) distinguishes between technological product innovation and technological process innovation. A technological product innovation can involve either a new or improved product whose characteristics differ significantly from previous products. A technological process innovation is the adoption of new or significantly improved production methods, including methods of product delivery.

R\&D activities form part of the process of technology transfer which, in turn, forms part of the innovation process. (Note, however, that some writers use the terms 'technology transfer' and 'innovation process' interchangeably.) It could be argued that technology

4 National Institute for Disability and Rehabilitation Research. 
transfer is the equivalent in science and engineering to the process of research utilisation in the social sciences, although, as the definitions below indicate, technology transfer involves and implies more than the use of research. ${ }^{5}$

Technology transfer is the process by which research and other new technologies are transferred into useful processes, products, and programs. Another way of saying the same thing is: technology transfer is the process by which a better way of doing something is put into use as quickly as possible. (Hodgkins 1989)

Technology transfer is a process by which existing technology is transferred or transformed to fulfil the user's needs. (Krull 1990)

... all the activities leading to the appropriate adoption of a new product or procedure by any group of users. 'New' is used in a special sense as it means any improvement over existing technologies or processes, not necessarily a chronologically recent invention. ... Technology transfer is not simply information dissemination; that is, it is not simply sending out information - whatever the form - and then passively awaiting its use. Technology transfer is a more active term. It implies interaction between technology sponsors and users and results in actual innovation. (Schmitt, Beimborn \& Mulroy 1985).

Technology transfer consists of efforts and activities intended to result in the application or commercialisation of laboratory-developed innovations by the private sector, State and local governments, and other domestic users. These activities may include, but are not limited to:

$<$ Technical/cooperative interactions (direct technical assistance to private sector users and developers; personnel exchanges; resource sharing; and cooperative research and development agreements);

$<$ Commercialisation activities (patenting and licensing of innovations and identifying markets and users); and

$<$ Information exchange (dissemination to potential technology users of technical information; papers, articles, reports, seminars, etc).

The twentieth century has seen an increased emphasis on knowledge production and the utilisation of research by users outside of academia for application to specific needs. This has been accompanied by an increased investment in research activities by both the public and private sectors. Arguably, investment in research to serve the needs of society was spearheaded by the US: the significant investments in R\&D by the federal government during and after the Second World War set a precedent for these kinds of activities in other countries. The circumstances of the expansion of R\&D activities in the US also led to a particular understanding of the innovation process and the role of research in technology transfer for many years to come. Generally speaking, innovation

5 See Walshok (1995:48-5I) for additional definitions of technology transfer. 
was conceived as a linear process "in which research largely preceded engineering and development” (Brooks 1996:21).

The following section provides a brief overview of the dominant conceptions of technology transfer and the innovation process as they have emerged in the US over the past half a century. It also highlights shifts in recent thinking from what might be considered old to new models of technology transfer, and thus research utilisation, in the science and engineering fields.

\section{The linear model of technology transfer and the innovation process}

Up until about the mid-1980s, the understanding of technology transfer in the American context assumed that it was essentially a linear and direct process in which scientific information fed directly into technological development (Brooks 1996:21; Salter et al 2000:27; Smith \& Barfield 1996:I; Wolfe \& Lucas 200 I:I76). The process was seen to involve consecutive stages, beginning with basic research and leading to "discovery, invention, commercial development, and introduction into a marketplace" (Walshok 1995:5I). In this respect, the dominant view of technology transfer in the US held that basic research was disconnected "from potential applications, product development, and market needs" (ibid). Instead, the discoveries of basic research merely suggested possible applications which would be "pursued through applied research, development, design, production, and marketing” (Brooks 1996:21).

Underlying this view of technology transfer was also the assumption that information - as a tangible entity - was the only product of research utilised in the innovation process. In this sense, information and knowledge are one and the same thing. Salter et al (2000:27) describe this view as follows:

The old view was based on the idea that the main output of publicly funded research was information. It focused on the informational properties of scientific knowledge, arguing that this knowledge is non-rival and nonexcludable. Non-rival means that others can use the knowledge without detracting from the knowledge of the producers, and non-excludable means that other firms cannot be stopped from using the information.

The main product from government-funded research was thus seen to be economically useful information, freely available to all firms. By increasing the funds for basic research, government expanded the pool of economically useful information thereby expanding opportunities for innovation.

\section{Non-linear models of technology transfer and the innovation process}

In the last decade or so, empirical studies have highlighted that the assumptions of the linear model are largely unfounded, or at the least, that they only represent a partial picture. Firstly, technology transfer and innovation are by no means linear processes (Smith \& Barfield 1996:I).

Instead, it has become clear that innovation is "a complex, interactive, non-linear process" (Lundvall \& Borrás 1997:29). Gibbons et al (1994, quoted in Kraak 1997:6I) use a 
sporting analogy to illustrate the inherent messiness, and the to-ing and fro-ing of the innovation process:

The notion of technology transfer ... cannot anymore be understood as a transmission of knowledge from the university to the receiver easily and usually with almost no follow up. Instead it is no longer like a relay race, in which the baton is passed cleanly and quickly from one runner to the next. Technology transfer looks more like a soccer game in which the university is a member of a team. To score it needs the aid of its team mates. The ball is passed back and forth constantly among the players who may include business people, venture capitalists, patent attorneys, production engineers, and many others in addition to the university faculty. This is why it has been suggested that technology interchange is a more appropriate phrase than technology transfer.

Furthermore, the nature of the innovation process varies across different industrial sectors. In the chemical and pharmaceutical industries, for example, innovation is based largely on new knowledge and the development of new products (Salter et al 2000:30-3I; Smith \& Barfield 1996:2). In the automobile or aircraft industries, on the other hand, innovation usually involves incremental improvements to specific components or complete redesign at the system level (ibid). Clearly, the nature of the scientific information and knowledge, and the uses to which it is applied in these different industries, gives rise to different processes of innovation. We discuss a few of these non-linear models of innovation and technology transfer in the following section.

\section{Stephen Kline's Chain-Linked Model}

The Chain-Linked Model, the most cited non-linear innovation model, was first reported in "Research, Invention, Innovation and Production: Models and Reality", Report INN-I, March 1985, Mechanical Engineering Department, Stanford University.

Dr Stephen Kline, an emeritus professor of Mechanical Engineering, has further developed and revised the Chain-Linked model in "An Overview of Innovation" (Kline \& Rosenberg 1986), and "Models of Innovation and Their Policy Consequences" (Kline 199la). In "Styles of Innovation and Their Cultural Basis " Kline (199lb) further elaborated the Chain-Linked model. The Chain-Linked model has also been referred to in many other documents, for instance in the Oslo Manual, the OECD's Technology I Economy Program and "Canada and the National System of Innovation".

Kline argues that the Chain-Linked model is consistent with a detailed evaluation of the nature of technology, the concept of innovation, and the failures of a simple linear model which are often assumed, and the necessity that the linear model be replaced with a more complex model in order to understand the nature of innovation. The Chain-Linked method emphasizes the socio-technical nature of industry and technology and the necessity to look at it as a complex system. In the model, the first path of the innovation process, central chain-of-innovation, begins with design and continues through development and production to marketing. The second path is a series of feedbacks. 
Figure I: The Chain-Linked Model of Innovation

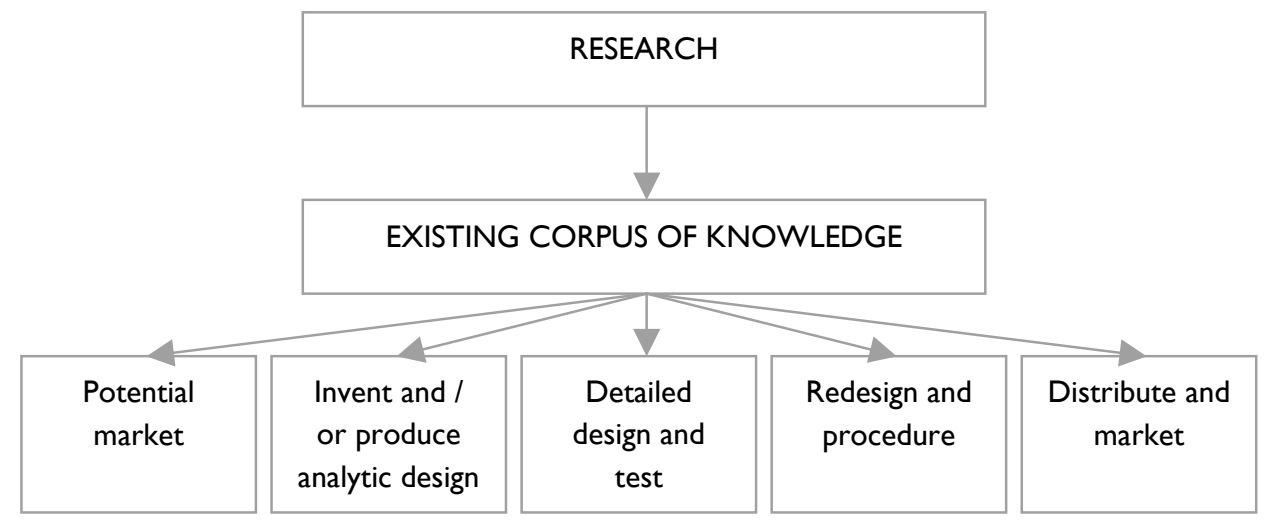

In the Chain-Linked model, the general process starts with a market-finding phase followed by design, production, marketing and distribution, and use phases. It differs from the linear model in a number of ways: there are multiple paths from which innovations may arise and many forms of feedback. Research is not normally considered to be the initiating step (in fact, research occurs in and contributes to all phases in the innovation process), and the primary source of innovation is now held to be stored knowledge and technological paradigms. It appears that this model more closely corresponds to the Japanese perception of the innovation process.

The Technology / Economy Program (TEP) of the OECD addresses also the need to integrate policies for science and technology with other aspects of government policy, particularly economic, social, industrial, energy, education and labour policies. 'Technology and the Economy; the Key Relationships', which is an outcome of TEP and published in 1992, also refers to the Chain-Linked model. This report underlines that the Chain-Linked model combines two somewhat different types of interaction. One concerns processes within a given firm (or possibly a group of firms working in a tightly-knit network). The second expresses the relationships between the individual firm and the wider science and technology system within which it operates.

At the level of the firm, the innovation chain is visualized as a path starting with the perception of a new market opportunity and/or a new science and technology-based invention; this is necessarily followed by the 'analytic design' for a new product or process, and subsequently leads to development, production and marketing. Feedback relations are generated: short feedback loops link each downstream phase in the central chain with the phase immediately preceding it and longer feedback loops link perceived market demand and product users with phases upstream. Problems identified by the processes of designing and testing new products and new processes often spawn research in engineering disciplines but also in science.

The second set of relationships link the innovation process embedded in firms and industries with the scientific and technical knowledge base and with research. In an industry-focused, interactive approach to innovation, a useful analytical distinction can be 
made between the two different uses of science and technology by firms, the use of available knowledge about physical and biological processes, and the work undertaken to correct and add to that knowledge. Generally, innovation takes place with the help of available knowledge. When corporate engineers confront a problem in technical innovation, they will call first on known science and technology, most often in serial stages. Only when those sources of information prove inadequate does a need arise for research. This analysis of the role of industrial R\&D in the innovation process applies directly to large firms. Firms below a certain size cannot bear the cost of an R\&D team.

\section{Ralph Gomory's Circle Model}

Ralph Gomory, a retired senior vice president of IBM and the current president of the Alfred Sloan Foundation, developed the Circle model of innovation as an alternative to the linear model (which he calls the 'Ladder' model). Gomory, in many articles, describes the main aspects of the Circle model.

In the Ladder paradigm, new things descend from the realm of science - step by step - into practice and become the genesis of an industry. Well-known examples in this respect include transistor and molecular biology. The belief that this kind of scientific dominance should translate into product dominance is probably, in many cases, a residue of the Second World War and the enormous impression made by the science-led, sciencedeveloped process of the atomic bomb. After the Second World War, a belief emerged that scientific dominance does translate into economic dominance. Scientists play the dominant role both in basic research and in the early phases of the industry because they are the only people who understand what's going on in sufficient detail. Therefore, in the early stages of a new industry, the Ladder paradigm predominates. Everything revolves around the new technology. According to Gomory, the Ladder paradigm is really a paradigm for getting things started, not for winning the longer race.

Much of the dominant thinking about innovation comes from the Ladder process because it has been so visible and so spectacular, involving the emergence of a new scientific effort and new products. We must make the cyclic development process more visible and to understand it better.

The cyclic process is a second relationship of technology and science. The cyclic development process is a process of repeated, continuous, incremental improvement. It is the process of following up what exists in manufacturing with the next model, which is designed, built and prototyped, tested, redesigned for manufacturing, put into production, and then in turn starts the next generation. This process is characteristic of the later (not the earlier) states of an industry. The type of industry in this case is discrete manufacturing, of which automobiles and transistors are very good examples. It is this cyclic development process that determines in the long run, then, who will be dominant in this industry. It is not as glamorous as the breakthrough type of invention; nevertheless, the progress that it causes is enormous.

The cyclic process is very different from the Ladder process. It is not science-based. It is based on what is already there, the existing product and its restrictions. So this type of development is very much restricted, not by a totally new idea, but rather by what is 
already there, whether that be the plant, or the tools, or the engineering team, or what they understand. Moreover, if new technologies are going to be part of this, they must fit into that very special world.

Gomory argues that the Ladder is characteristic of the early stages of an industry and the Circle is characteristic of later stages. However, it is the Circle, not the Ladder that has been decisive in the industries in the US that are in trouble - automobiles, semiconductors, and television. The notion of investing in R\&D, consistent with the Ladder approach, is that you put the R\&D here and the product pops out there. That is very, very different from what is really encountered if participating in a cycle development process. It is the industrial success that causes the R\&D spending, not the other way around.

The wrong mental picture hurts a great deal. Consider the picture brought to mind by the phrase, 'commercialisation' of new technology. Most people believe in the notion that commercialisation means to take something new and make it commercial, whereas the essence of the cyclic development process rests in defining something which is already commercial. When one talks about the commercialisation of scientific discovery, one is relegated to use of phase one, or the Ladder process.

John Alic argues that the Circle approach, compared to the linear model, gives equal weight to technical virtuosity in all of the functions - research, design, production, and marketing - and produces a model that stresses the importance of close coupling among them.

\section{The Alic-Branscomb Model}

Dr. John Alic, a senior associate of the Office of Technology Assessment of the US Congress, and Dr. Lewis Branscomb, from Harvard University, have studied the evolution of the tacit US technology policy in the years after the Second World War. In their books, Empowering Technology: Implementing a US Strategy and Beyond Spin-off: Military and Commercial Technologies in a Changing World, they have greatly contributed to the studies related to specification and procedure of evolution of the linear model that is tied to the post-war tacit US technology strategy.

John Alic regards 'innovation' as a social process involving the application of knowledge, together with other inputs, to design, develop, create, and market some products. The output of innovation can include intangible service products as well as physical objects and systems. The artifactual product should be viewed as derivative, the consequence of research, design, development, production, and marketing activities - of what people and organizations know (declarative knowledge) and can do (procedural knowledge).

Technological innovation, especially in the later stages often called commercialisation, is an activity pursued by business firms.

The core activity of commercialisation and the culminating stage of innovation is engineering design and development - an activity sufficiently different from R\&D that we might call it D\&D. As an extension of research, as in R\&D, development implies reducing new knowledge to practice - verifying and validating experimental results and theoretical 
predictions, exploring specific cases, and determining the accuracy and limits of mathematical models and methods. However, when coupled with design, development implies the steady refinement of concrete products, processes and systems through an iterative process of conceptualisation, preliminary design, analysis, testing and redesign. This is the everyday technical work of private firms, often called product development or product engineering (or process development, software development, and so on). Instead of thinking of design and development (activities in which knowledge is applied) as D\&D, reserving R\&D for activities that generate knowledge, the latter term has entered into common use to stand for either or both. Although practitioners, understanding the distinctions, do not have much trouble communicating among themselves, the broad range of activities encompassed by R\&D in its now-common usage sometimes leads to confusion among economists, policy analysts, and other observers.

Innovation results from the artful combination of new knowledge with, typically, a great deal of existing knowledge. New knowledge and methods originating in R\&D may be critical. At the same time, a successful innovation, leaving aside exceptions such as defence systems, is one that meets the test of the marketplace. Successful innovation depends more directly on D\&D, though not of course to the exclusion of R\&D. Nevertheless, the latter may be far removed in time and place from the design and development that precedes marketplace success.

Alic and Branscomb argue that central to the national system of any advanced economy will be mechanisms both for generating new knowledge through R\&D and for applying knowledge, new and existing. Less developed economies with fewer needs for new knowledge may nonetheless benefit from R\&D tailored specifically to their situation.

Despite various attempts to develop alternatives to the linear model of technological innovation, Brooks (1996:2I) argues that the linear model is not without substance: It still provides a plausible description for many of the radical paradigmshifting technological innovations during the cold war period, not only in defense but also in a number of commercial areas. The most classic case is the development of nuclear weapons and nuclear power following the discovery and theoretical explanation of nuclear fission, but other examples include the transistor, the laser, genetic engineering, and many biomedical technologies.

\section{Model for understanding the innovation of complex technologies - Kash,}

\section{Auger \& Li}

Much of the discussion around technological innovation has moved beyond the former linear/non-linear classification. There is an increasing recognition of the role of various organizational forms as necessary in technological innovation.

Networks involve linkages and relationships that make it possible to access, create, synthesize and diffuse the diverse tacit and codified knowledge necessary for the innovation of complex technologies. (Kash et al 2002: I 65) 
In a very useful analysis of the underlying dynamics of complex technologies, Kash and co-authors distinguish between three patterns of technological innovation, i.e. transformation innovation, normal innovation and transitional innovation.

Transformational innovation is distinguished by the innovation of first-of-a-kind technologies. According to Kash et al (2002:168),

When the first-of-a-kind technology is complex, a network of organizations that range from complementary asset suppliers to end-users must be formed in order to incorporate the diverse knowledge needed for the innovation. Thus, within the transformational innovation pattern both a new network and a new technology must be designed and built, in part, through a trial and error learning process.

The normal pattern is distinguished by

... innovations that deliver enhancements of established technology designs, for example, the ever more powerful microprocessors emerging from incremental innovations. Incremental innovations are predominantly the product of cumulative learning within the network that was established to innovate the first-of-a-kind technology (idem: 169).

Within the transitional innovation pattern, innovations

... deliver major redesigns, for example, the synthesis of electronics and mechanics. Like the technologies, the networks that carry out transitional innovations must undergo major redesigns. The most distinctive characteristics of the network design is that new core capabilities must be integrated or merged to create a new network with the needed innovation capabilities. Thus the redesigned network must be able to access, create and synthesize knowledge that did not previously exist in the network (idem: $169-170$ ).

The possibility of these three innovation patterns is described in Figure 2. The transformational pattern is represented by the square at the beginning of the trajectories; the normal pattern by the circles on the trajectories and the transitional pattern by the triangles that connect the trajectories. Table 3 summarises the main organisational and cultural requirements associated with each of the innovation patterns.

This approach opens up many new possibilities in terms of how research - in all its different forms and with its range of possible outputs - can contribute to technological development in its broadest sense. Clearly, it also has implications for policies and strategies relating to research utilisation and innovation. 
Figure 2: Technological innovation patterns

\section{Three Innovation Patterns}

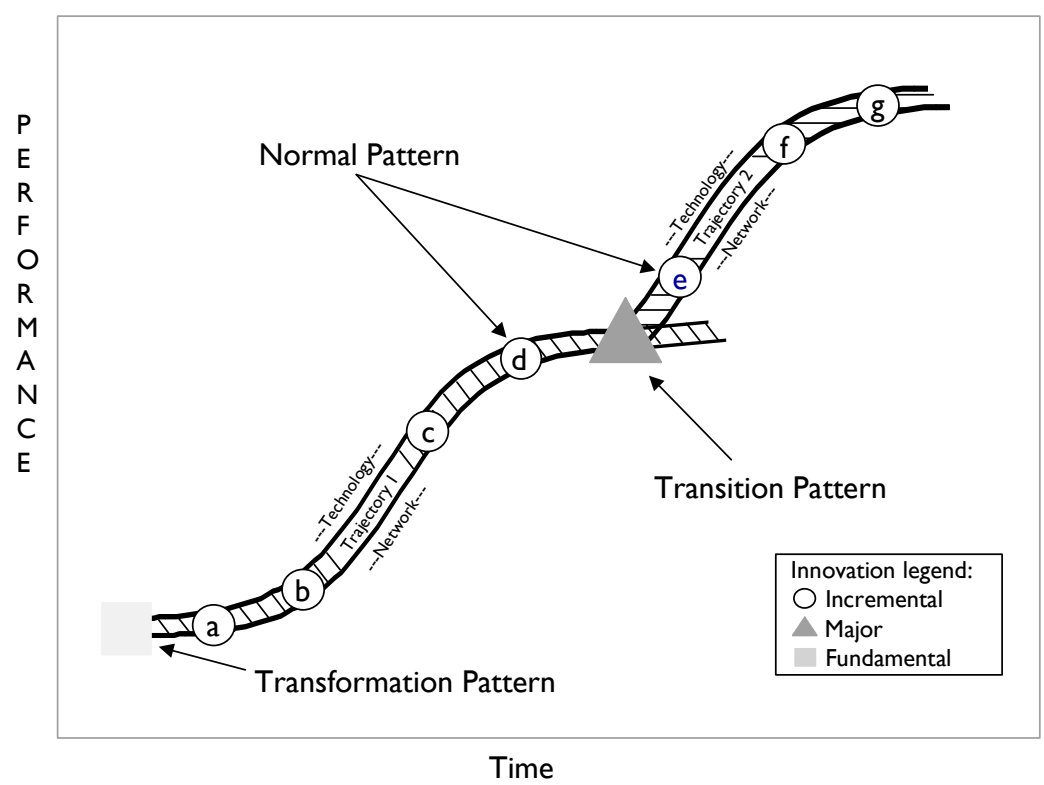

Table 3: Innovation patterns with their organisational and cultural requirements

\begin{tabular}{|c|c|c|}
\hline Innovation pattern & Organisational requirements & Cultural requirements \\
\hline Transformational & $\begin{array}{l}\text { Ability to access, create and } \\
\text { synthesize knowledge from } \\
\text { sources and with organizational } \\
\text { arrangements that are new } \\
\text { - Repeated trial and error } \\
\text { - Ability to learn from failures }\end{array}$ & $\begin{array}{l}\text { High level of trust with } \\
\text { those not previously } \\
\text { known } \\
\text { - Comfort with tacit } \\
\text { knowledge } \\
\text { - Comfort with codified } \\
\text { knowledge } \\
\text { - Centralized decision- } \\
\text { making } \\
\text { - Comfort with uncertainty }\end{array}$ \\
\hline Normal & $\begin{array}{l}\text { Ability to self-organize to } \\
\text { facilitate rapid learning and } \\
\text { unlearning } \\
\text { - Problem-solving R\&D and non- } \\
\text { R\&D knowledge } \\
\text { - Consensus on next step }\end{array}$ & $\begin{array}{l}\text { High level of trust with } \\
\text { those previously known } \\
\text { - Comfort with tacit } \\
\text { knowledge } \\
\text { - Comfort with codified } \\
\text { knowledge } \\
\text { Consensus decision- } \\
\text { making }\end{array}$ \\
\hline
\end{tabular}


Table 3 Continued

\begin{tabular}{|c|c|c|}
\hline Innovation pattern & Organisational requirements & Cultural requirements \\
\hline Transitional & $\begin{array}{l}\text { Ability to integrate separate } \\
\text { organizational networks and } \\
\text { bodies of knowledge into new } \\
\text { network and knowledgebase } \\
\text { - New routines and heuristics } \\
\text { developed by trial and error } \\
\text { Ability to meld cultural } \\
\text { differences }\end{array}$ & $\begin{array}{l}\text { - High level of trust with } \\
\text { those previously known } \\
\text { and unknown } \\
\text { - Comfort with tacit } \\
\text { knowledge } \\
\text { - Comfort with codified } \\
\text { knowledge } \\
\text { - Centralized decision- } \\
\text { making }\end{array}$ \\
\hline
\end{tabular}

The importance of "tacit' knowledge in the process of technology transfer A second assumption of the linear model that has been called into question is that the informational properties of scientific knowledge alone are utilised in the innovation process. Information and knowledge have been shown to be significantly different creatures. While the dissemination of information to potential users is a necessary condition of technology transfer, it is by no means sufficient. In this regard, a distinction between 'codified' and 'tacit' knowledge is usually made. According to Salter et al (2000:60):

Codified knowledge is that which comes in written form, for example a scientific report. It involves more than just the inscription of that information, but also the development of the empirical and/or theoretical underpinning. Tacit knowledge refers to the wider, non-codified intelligence brought to any task by those who design or carry it out.

Kraak (1997:54) defines tacit knowledge as

... the experience employees across the occupational spectrum have acquired through years of employment in a given enterprise: their knowledge of the production environment, their ability to identify flaws in the production process and quality defects in the final product, their learning-by-doing and sharing of shop floor wisdom. ... It bears a critical relationship with the capacity to reconfigure existing production information, technological knowledge and expertise to yield new designs, new products and increased market share.

It is argued that codified knowledge has no value, or is largely useless to potential users if it is not accompanied by the relevant tacit knowledge (Salter et al 2000:59-60). Clearly, this applies across all the science cultures. Within the natural sciences and engineering, this has come to be termed the 'absorptive capacity' of firms and industries. In recent years there has been an acknowledgement that users of research in fact require certain prior knowledge and skills in order to evaluate, translate and ultimately apply and utilise scientific information generated through research. Cohen \& Levinthal (1990:128), for instance, emphasise the role of prior knowledge in developing absorptive capacity:

The ability to exploit external knowledge is thus a critical component of innovative capabilities. We argue that the ability to evaluate and utilize 
outside knowledge is largely a function of the level of prior related knowledge. At the most elemental level, this prior knowledge includes basic skills or even a shared language but may also include knowledge of the most recent scientific or technological developments in a given field. Thus, prior related knowledge confers an ability to recognize the value of new information, assimilate it, and apply it to commercial ends.

Salter et al (2000:29-30) take this a step further and introduce the idea of 'research as capability':

The new approach to the economics of publicly funded research suggests that the informational view of knowledge substantially undervalues the extent to which knowledge is embodied in specific researchers and the institutional networks within which they conduct their research. An informational view of knowledge also misrepresents the nature of the innovation process, implying that scientific knowledge is 'on the shelf, costlessly available to all comers' (Rosenberg, 1990, p. 165). It fails to appreciate the extent to which scientific or technical knowledge requires a substantial capability on the part of the user as well as the producer.

In this respect, Salter et al (2000:28) argue "that there needs to be a distinction between information as a commodity and knowledge as the capacity to use information." The terms 'information' and 'knowledge' are often used interchangeably and, according to Salter et al (2000:60), this causes confusion about which of the two firms draw on from public sources:

... the difference in terminology is important for understanding the role played by research. The traditional justification for government-funded research relies on the 'public good' qualities of information, i.e. data and conclusions from research. Yet the evidence from science policy studies indicates that what firms draw upon is not simply information, data or the conclusions of research but something more complex, namely knowledge. In other words, firms are less likely to use specific data or conclusions (information) than they are to draw upon new understandings or approaches in searching out solutions to innovation problems. As noted earlier that the scientific process in innovation involves finding analogies for new problems, and drawing upon a stock of knowledge in exploring how the analogy might be applied to new situations. Specific conclusions, usually drawn from research studies conducted for other purposes, are rarely crucial in this process, but on-going interaction between those who add to, and understand the stock of knowledge, and those who apply it, is essential.

\section{Ways in which research can be utilised in the innovation process}

More recent views on technology transfer imply that different contexts and types of knowledge can be used in different ways. These range from the direct application of scientific knowledge to specific technological problems (non-epistemic uses), to expanding the general pool of useful knowledge (epistemic uses). There is also an emphasis on the knowledge, skills and know-how required to transform and apply knowledge. 
Wolfe \& Lucas (200I:I78) provide a useful description of these dimensions of knowledge utilisation, focussing on the

... two roles that science plays in supporting innovation: one as an expanding pool of theory and problem-solving techniques deployed in industrial $R \& D$, but not necessarily new science; the other as a direct source of new technological possibilities pointing the way towards new solutions to old problems. The primary finding was that the role of science as a broad pool of knowledge is more relevant than the direct research findings of scientific research. Current research is generally reported as less directly relevant to the innovative activities of industry. Industrial $R \& D$ managers value the scientific background and training of their R\&D staff more highly than the current research activities of university-based researchers ...

\section{Technological problem-solving}

Science and engineering R\&D can be "a source of practical help and assistance" (Senker, Faulkner \& Velho 1998:125) - in the form of advice, information or solving specific problems - applied directly to the development of new, or the improvement of existing products and processes. However, while scientific research, knowledge and expertise can be used in a direct manner to solve specific technical problems, research has shown that it might have a more diffuse role to play in technological development and innovation. Salter et al (2000:37) describe this as a function of academic research as follows: New scientific research often expands the underpinning knowledge for technological problem solving. It provides engineers with tools and techniques to undertake practical applications. It helps to inform technical choices and provides new techniques and tools for technologists to use in their technical problem solving.

According to Salter et al (2000:65), a recent study indicated that this more indirect use of research was evident in three times as many cases than the direct application of research findings in firms. This use of research could be likened to Weiss' enlightenment function of social research in the policy-making process.

\section{New instrumentation and methodologies}

R\&D activities can lead to the development of new instrumentations and scientific methods and techniques, either because of directed applied research, or as an outcome of basic research. Instrumentalities here refer to "the instruments and associated techniques and skills used to conduct experiments and tests" and therefore refer to using the methods of science itself (Senker, Faulkner \& Velho 1998: I I3). According to Salter et al (2000:63),

Some of these new methods are eventually adopted in industry. Examples include electron diffraction, the scanning electron microscope, ion implantation, synchrotron radiation sources, phase-shifted lithography, and superconducting magnets. All of these are now vital technologies in key growth industries ... 


\section{Adding to the pool of useful knowledge}

Science and engineering research is also a vital source of new ideas or technological knowledge for industrial firms (Salter et al 2000:59; Senker, Faulkner \& Velho 1998:125). This applies especially to basic research. According to Senker, Faulkner \& Velho ( I998: I I3), "from citation studies of patents ... and the 'technology' literature ... we know that industrial researchers in some fields make quite heavy use of the current scientific literature, especially at times when new knowledge is emerging." In other words, contrary to the current emphasis on 'relevant' applied research for industry and "the commercialisation of academic inventions", recent studies have shown that "the flow of material inputs to new product development from academia into industry is negligible" (Senker, Faulkner \& Velho 1998:I28). In other words, basic research can stimulate and enhance the "power of R\&D done in industry, rather than providing a substitute for it" and expand "available technological opportunities" (Salter et al 2000:60).

Salter et al (2000:66) provide an example of the linkage between basic research and applied engineering science:

... insights from basic research often trickle down to industry via engineering schools, which draw upon fundamental sciences to develop technical knowledge for engineering and design. There is a strong feedback loop between engineering knowledge and fundamental science; for example, knowledge about electrical engineering often depends on fundamental discoveries in physics or mathematics ...

\section{'Knowledge spillovers'}

Much of the discussion so far has focused on the involvement of publicly funded research in universities and government laboratories. Firms themselves conduct a significant proportion of industrial R\&D. Especially where firms are spatially clustered, knowledge spillovers can increase opportunities for research utilisation. Salter et al (2000:45) define knowledge spillovers as follows:

The notion of a 'spillover' refers to the fact that firms may benefit from the $R \& D$ efforts of other firms or institutions in the vicinity that are conducting research in related scientific or technological fields. Firms can thus gain these benefits without having to pay for them.... Spillovers are important because they can augment the productivity of a firm or industry by expanding the general pool of knowledge available to it and therefore play a critical role in translating research into practice.

While innovation is becoming increasingly globalised, according to Salter et al (2000:45), there is also evidence to suggest that firms "often rely on a local infrastructure to support their research activities." The physical proximity of firms (what Salter et al call the "geography of innovation") facilitates knowledge spillovers and, therefore, enhances technological development.

\section{The institutionalisation of technology transfer}

Over the past couple of decades, a variety of institutional forms for the utilisation of (predominantly) natural science and engineering products within the larger innovation 
process have emerged. We discuss six such "institutional forms". Although the focus is to some extent on "institutions" that facilitate technology transfer between higher education institutions and industry, the underlying principles are equally applicable to other public sector R\&D performers in their relationship with industry.

\section{Long-term strategic alliances}

Long-term higher education-industry alliances are normally based on a coincidence of interest or mutual affinity between the scientific concerns of the company and the higher education institution. These scientific concerns are typically wide ranging, and, compared with corporate in-house R\&D, unfocused, often involving the funding of a whole new (embryonic) field of research or an entire academic department. They are established with the aim of drawing on the discovery skills and expertise of academics in the new area. This kind of funding is high risk, but can yield beneficial results (cf. Webster \& Etzkowitz 1998:53; Slaughter \& Leslie 1997:164).

Long-term coalition between a single company and a university science department has recently been actively promoted as an alliance that allows mobile 'innovation teams' to cross the institutional boundaries of industry and academia, providing a much more flexible and effective innovative environment for the large corporate partner. The attractiveness of this type of coalition to industry no doubt reflects the growing need for more flexible organisational structures within which innovation can occur (Webster \& Etzkowitz 1998:53).

\section{Co-locational collaboration}

Another form of long-term collaboration between industry and higher education described by Webster and Etzkowitz (1998:55-6) involves a co-locational agreement. Here, a company establishes a strategic research laboratory on a campus in property rented from a higher education institution. A tenancy agreement forms the basis of the contract between the two parties. The company unit is strongly product-oriented even though it conducts some basic research.

Collaboration here occurs on an informal basis through the development of informal links with neighbouring scientists working within the cognate department. These coalitions clearly seek to maximise the possibility for collaborating with academia while taking very little risk on matters such as intellectual property rights, control over employees, and research that meets the applied needs of the company (Webster \& Etzkowitz 1998:55-6).

\section{Technology transfer offices}

The rise in collaborative ventures between industry and higher education has been accompanied by a growing awareness within the higher education sector of the commercial value of their research activities. In response to this awareness, many higher education institutions have established agencies - most commonly known as 'technology transfer offices' - designed to exploit their own intellectual property (Etzkowitz \& Webster 1998:36-7). 
Within this context, 'technology transfer' is regarded as most productive when it involves "a continuous flow of new knowledge and ideas, rather than the occasional transfer of technology" (The Business-Higher Education Forum in Bell \& Sadlak 1992:229). This means "the old notion of technology transfer as a one-time hand-out from the university to the firm has been replaced by a broader vision, which encompasses an on-going twoway exchange between the partners" (ibid).

This broad definition of the highly complex process of technology transfer clearly recognises that direct communication between 'source' and 'user' in the choice of the knowledge to be produced and transferred enhances the success of collaboration for all parties concerned. It is then exactly here where the involvement of a technology transfer office can be vital. Regardless of whether this office is located on or off campus, it can and should, through clear direction, the right level of resources, and effective links with other commercialisation activities, enhance the level of mutual understanding and cooperation between the higher education and industry partners. More concretely, it should facilitate contacts between higher education and industry practitioners and raise consciousness both inside and outside the higher education environment about the potential commercial value of research products and, in particular, about licensing opportunities, intellectual property rights, and the economic import of technology transfer. In this way, it should not only promote a broad network of knowledge exchanges, but should ensure that this network is firmly grounded in sustained relationships of mutual interest and mutual trust (OECD 2002:6405; Peters \& Etzkowitz 1990:432-3; Scott et al 200I:20-I).

\section{Academic incubators}

Etzkowitz et al (2000:5I) explain that a 'traditional incubator' will offer

... common use conference space; office support services, such as receptionist, fax, copier and Internet access; and business support services, such as access to capital, business plan assistance, mentors and assistance when the start-up company is about to graduate from the incubator programme.

In addition to the traditional support services, 'academic incubators' also offer ... access to university facilities, such as libraries, specialised scientific equipment and significant computing facilities. Faculty is also available to consult with the companies, and students are a ready source of employees or interns. If the university has a business school, students are also able to provide marketing support and business research'. (ibid)

A university-based business incubation programme offers several types of business opportunities. It may include companies entrepreneured either by university faculty, students and alumni or by outside entrepreneurs who seek to commercialise technology developed by the university. Of central importance to the success of such a business programme is "a theme or clear focus" (Etzkowitz et al 2000:5 I). For faculty and students to interact with the companies in the incubator there must, after all, be a match between the academic or research strengths of the university and the type of companies encouraged and actively recruited to the incubation programme. A lack of such a match 
makes meaningful interaction between the university host and its incubator companies much less likely (Etzkowitz et al 2000:5I).

When an incubation programme is planned and managed with clear direction, such a programme is expected not to only inspire individual firm growth, but also, in doing so, to lead to an increase in research collaboration, student employment, faculty consulting, use of facilities and/or financial contribution to the university. Beyond this, some incubation programmes and firms "act as transmission belts of knowledge and 'best practices' from the university to other firms in the region and in the reverse direction, as well as a transmitter of research problems and consultation opportunities" (Etzkowitz et al 2000:56). Thus, academic incubators as well as incubator firms carry the potential to make a substantial contribution to the successful transfer of technology by means of closer collaboration between industry and higher education.

\section{Science parks}

The academic goal of a science park is to increase the number of scientists in the region in scientific areas in which the higher education institution has strength and/or wants to develop strength (Etzkowitz et al 2000:45). A higher education institution does this by inviting tenants to set up companies on a piece of under-utilised property that is owned by the institution and that is, if not directly adjacent, at least in very close proximity to it (Scott et al 2000:20).

The higher education institution then establishes both formal and operational links with the park and its tenants to directly encourage the growth and formation of knowledgebased business skills in the park. The higher education institution also, more importantly, becomes involved in the managerial function of the park. This is important for two reasons. First, through managerial involvement the higher education institution can have a direct say in the actual composition of the tenants in the park. Here, the institution should decide upon the desired operational nature of the tenants (that is, whether to include manufacturing, non-manufacturing, commercial, and/or non-commercial organisations) as well as upon the commercial focus of their activity (Stankiewicz 1998:135). The latter is crucial for without sufficient overlap between academic strengths and the economic activities of the tenants, the park is unlikely to yield expected benefits (Johnstad 1987:299-300; Stankiewicz 1998:142). Second, managerial involvement can strengthen actual linkage and cooperation between the higher education institution and members of its science park by encouraging joint participation in selected ventures (Johnstad 1987:299; Stankiewicz 1998:145). Without such direct support both informal and formal relations between the participating academic and corporate communities is likely to suffer severely (cf. Webster \& Etzkowitz 1998:57).

The rationale behind the science park is found in the concept of 'localised knowledge spillovers' (Scott et al 200I:19). Here it is argued that firms operating near sources of knowledge such as universities can transfer knowledge and technology and so introduce innovations at a faster rate than rival firms located elsewhere (Bell \& Sadlak 1992:23 I-4; Hicks 1999: I0; Salter et al 2000:45; Scott et al 2001:19). In addition to augmented innovation productivity, the geographical agglomeration of knowledge practitioners, such as through a science park, is believed to strengthen economic development and innovation 
because of the personal interaction between practitioners. In light of the person-embodied nature of much technological knowledge and the concurrent importance of face-to-face interactions, such direct personal contact becomes imperative. This appears to be particularly true when dealing with the uncertainty inherent in the development of new technology (Salter et al 2000:45-9; Bonaccorsi \& Piccaluga 1994:24I).

This entire line of argument can, of course, be criticised "for relying on an outdated, linear model of innovation, which assumes that scientific knowledge can be transferred unproblematically from a research university to an adjacent park for development" (Phillimore in Scott et al 200I:19-20) (see Section 4.4). What is more, reliance on this argument may simply serve to overly concentrate, rather than distribute the knowledge and skills needed for competitive innovation. Criticisms of this nature appear to be corroborated by rather ambivalent findings concerning the actual success of science parks. According to Stankiewicz' review (1998:138), several studies report that while science parks may be successful in attracting tenants who are apparently satisfied with their locations in the parks, this does not mean that there presence is necessarily accompanied by any substantial interaction or cooperation with their higher education host. This rather disappointing finding appears to suggest that proximity may, indeed, not be enough to stimulate closer collaboration between higher education and industry.

Despite such negative sentiments, numerous authors (cf. Etzkowitz et al 2000:45; Webster \& Etzkowitz 1998:57; Johnstad I987:300-I) still maintain that science parks when approached with the necessary foresight and commitment - can have a significant contribution to make in encouraging and facilitating dynamic entrepreneurial behaviour. Science parks do, after all, create a meaningful opportunity for intellectual osmosis between industry and academia to occur. When realised, when knowledge and technology is transferred, firms will grow and new ones will be established. As a result of such economic growth near the higher education institution, jobs for graduates will be created, consulting opportunities for faculty will be enhanced, and the possibility of joint research projects will be strengthened. In addition, the higher education institution may benefit from greater industrial funding, as well as from the general growth injection experienced by the local economy.

Thus, science parks may well be powerful instruments to build effective relations with industry and transform the local economy, but from our review it is clear: as a long-term commitment they require a potent combination of strategic planning, inspired vision and unwavering staying power to see this potential fully realised.

\section{Academic spin-off companies}

"Spinning off is the entrepreneurial route to commercialising knowledge developed by public research and as such is attracting a great deal of attention" (OECD 2002:4I). Much of this attention has been focused on the academic spin-off company as one of the most important agencies that can act as an interface between industry and higher education in the commercialisation of research products.

Webster and Etzkowitz (1998:58-9) explain that such spin-off companies arise where individual academics or academic institutions form a separate company to exploit and 
commercialise their research. By so translating research results into economic products of value and then taking the next step in forming a new firm to bring such products to the market, the higher education sector is directly entering the economic domain traditionally reserved for the corporate sector alone (see Cohen et al 1998:183; Etzkowitz et al 2000:4I; Etzkowitz \& Webster 1998:23).

For Mustar (1998:218), the key to the success and growth of these spin-off companies lies directly in their "capacity to create partnerships and alliances with a variety of actors". This is, as Mustar (1998:218) rightly notes, "a far cry from the traditional image of the heroic, solitary entrepreneur. Regardless of their talents, high-tech entrepreneurs can do precious little on their own". Thus, to succeed - that is, to simultaneously create a new company and exploit its markets - academic entrepreneurs need to be intimately integrated into networks of interactive partnerships and alliances (Salter et al 2000:33; Mustar 1998:218).

Such partnerships and strategic alliances concern a number of sectors. Firstly, creating and developing a spin-off company has a cost. Hence, the capability of the entrepreneur to convince others to invest in a particular project is crucial. Here, financial partnerships including those with public funding agencies - are decisive to ensure the creation and early development of a company (see Mustar 1998:2 I8). In this regard, Webster and Etzkowitz (1998:58-9) note that the capital of new spin-off companies is increasingly likely to come from the academic establishment - it now prepared to act as a venture capital investor. This trend is yet another indication of the way in which higher education is directly penetrating the industrial domain.

Mustar (1998:218) goes on to show that those spin-off companies that have enjoyed the highest growth rates have from the outset been involved in partnerships in the field of technology and innovation. Within such partnerships "the company collaborates with other firms, not merely in subcontracting terms, but increasingly often through the codevelopment of new products" (ibid). These market-oriented alliances are established first with suppliers, but also with customers, "whose presence becomes indispensable as the project progresses gradually towards the marketplace". Mustar (1998:219) adds that the most efficient companies have indeed set up "a sophisticated system of relationships with their future customers in order, first, to define and design new products and, second, to ensure follow-up assessment of the uses they are put to".

Furthermore, spin-off companies entrepreneured by academic researchers are usually tied, at least initially, to a research centre in the parent higher education institution. Mustar (1998:219) suggests that far from cutting the "umbilical cord" with academic research, successful spin-off companies have not only maintained very close links with their original research centre, but have in fact developed links with other research centres as well. Within this context, a spin-off company may choose to generate its own research team, to employ distinguished scientists on a consultancy basis, to enter cooperation agreements in $R \& D$, and to continue participation in the publication of scientific articles. According to Mustar (1998:219), "this capacity for exploration in an emerging science increases their chances of having original ideas and of seizing new opportunities." 
Thus, the most successful companies created by academic entrepreneurs 'are very close both to their clients and to academic research. They are constantly undergoing a process of adaptation and exchange between science and the marketplace' (Mustar 1998:219).

This process involves substantial national and international interaction and acknowledges the importance of partnerships and alliances across all fields. In fact, such interaction and collaboration that gives a company its ability to anticipate and its strategic capacity to analyse technologies and customers. At the same time, these factors enable it to bring into play and accumulate the varied resources and skills that its development requires (Mustar 1998:220).

Concluding comments: This concludes our review of different models and frameworks of the utilisation of knowledge and research in four domains: agriculture, social science, health science and science and engineering. Building on some of the insights presented here, we present in the final section of this review a conceptual framework that attempts to model the logic and dynamics of research utilisation more generically. The framework is based on the seminal work of Barry Bozeman (2000) on 'technology transfer'. 
CHAPTER 5

RESEARCH UTILISATION: A HEURISTIC FRAMEWORK

This section is introduced by formulating some basic precepts which underpin the framework. We then present the basic framework, followed by a discussion of the notion of 'research utilisation trajectories', which is introduced in order to make sense of various modes of utilisation.

\subsection{Basic precepts of research utilisation}

PRECEPT I: Forms of research utilisation are strongly influenced by the nature of the research / mode of knowledge production (research modes / modes of knowledge production)

PRECEPT 2: The utilisation of research occurs differently in different knowledge or science fields (knowledge domains)

PRECEPT 3: Taken together, precepts I and 2 logically imply a wide variety of research utilisation modalities. In order to emphasize the dynamic nature of these modalities, we introduce the notion of 'research utilisation trajectories' (RUTTs)

PRECEPT 4: The effectiveness of research utilisation is contingent on the specific configuration of a number of interrelated factors (utilisation effectiveness).

The discussion in Chapter 3 has shown how shifts in modes of knowledge production have occurred and continue to occur both within higher education and industry. Old distinctions between basic and applied have made way for new ones: Mode I and 2, the notion of strategic science, research within the context of application, and so on. Our first precept captures these shifts as well as the rather obvious point that the way in which we use research is (at least partially) a function of the kind of research that we engage in.

For the sake of simplicity we will adhere to the latest Frascati (OECD 1994) classification of research into three categories: 'basic fundamental', 'basic strategic' and 'applied'. These definitions point to the motivating interest of a researcher:

$<$ Basic fundamental research: Is the scientist motivated/driven by an interest purely in curiosity/discovery/knowledge for the sake of knowledge?

$<$ Basic strategic research: Is the scientist - albeit first and foremost driven by curiosity/intellectual concerns - also mindful of possible practical and economic and social applications/utilities in the future?

$<$ Applied research: Is the scientist driven by a direct and short-term interest/concern to solve a peculiar practical/technical problem?

These differences in cognitive interests (Habermas's notion of 'epistemic interests'), when related to other aspects of the research enterprise, are illustrated more clearly in Table 4. 
Table 4: On modes of knowledge production

\begin{tabular}{|c|c|c|c|c|c|c|}
\hline MODE & Motive & $\begin{array}{l}\text { Time- } \\
\text { frame }\end{array}$ & Audience & $\begin{array}{l}\text { Funding } \\
\text { source }\end{array}$ & Dissemination & $\begin{array}{l}\text { Quality } \\
\text { control }\end{array}$ \\
\hline Fundamental & Curiosity & Indefinite & $\begin{array}{l}\text { World of } \\
\text { science }\end{array}$ & $\begin{array}{l}\text { Scarce } \\
\text { Own } \\
\text { institution } \\
\text { Public } \\
\text { funding }\end{array}$ & $\begin{array}{l}\text { Scientific } \\
\text { publications/ } \\
\text { Presentations }\end{array}$ & Peer review \\
\hline Strategic & $\begin{array}{l}\text { Curiosity } \\
+ \text { Utility }\end{array}$ & $\begin{array}{l}\text { Long- } \\
\text { term }\end{array}$ & $\begin{array}{l}\text { World of } \\
\text { science and } \\
\text { other as yet } \\
\text { unidentified } \\
\text { beneficiaries }\end{array}$ & $\begin{array}{l}\text { Public } \\
\text { funding } \\
\text { Other } \\
\text { sources }\end{array}$ & Scientific forms & $\begin{array}{l}\text { Peer review/ } \\
\text { Potential } \\
\text { users }\end{array}$ \\
\hline Applied & Utility & $\begin{array}{l}\text { Short- to } \\
\text { medium- } \\
\text { term }\end{array}$ & $\begin{array}{l}\text { Specific } \\
\text { users/ } \\
\text { beneficiaries }\end{array}$ & $\begin{array}{l}\text { Private } \\
\text { funding }\end{array}$ & $\begin{array}{l}\text { Confidential } \\
\text { contract reports/ } \\
\text { strategic briefings }\end{array}$ & $\begin{array}{l}\text { User } \\
\text { satisfaction }\end{array}$ \\
\hline
\end{tabular}

It is important to realize that the mode of research already 'pre-determines' or at least 'influences' the following:

$<$ The form and channels of dissemination

$<$ The perceived value of the research output (scientific/social/economic), and

$<$ The intended target audience or beneficiaries of the research output(s).

The second precept introduces the notion of domain dependency. As our historical overview has shown, the nature of knowledge production and utilisation varies considerably across different scientific domains. This is mainly so because of fundamental differences in the 'units of analysis' as well as (or because of) different methodological practices. The differences between animate and inanimate objects, between social and physical phenomena, between historical and a-historical objects, have - not surprisingly over the years produced an inevitable methodological pluralism. Similarly, the differences between experimental research practices, whether in laboratories or on experimental farms, or between applied social surveys and programme evaluation studies, or between computer simulations and real-life field studies, are vast.

In addition to the very different methodological practices amongst the domains of scientific inquiry, there are also other equally important social-epistemological differences in the relationship between the scientist and his/her scientific domain. The big contrast here is between the human and natural sciences. In the human sciences (social sciences and humanities), the scientist studies and investigates the social world. The social 'object' is another conscious, rational and reflective human being. The study objects of the natural, health and engineering sciences do not have these features. As Anthony Giddens has persuasively argued: whereas the natural sciences interpret and explain the world, the human sciences very often have to interpret an already interpreted world. He calls this the "double hermeneutic" of the human sciences. 
In a paragraph that has become a classic statement of this sentiment, Alfred Schutz contrasts the world of physical nature with social reality in the following manner:

The world of nature, as explored by the natural scientist, does not "mean" anything to molecules, atoms and electrons. But the observational field of the social scientist - social reality - has a specific meaning and relevance structure for the human beings living, acting and thinking within it. By a series of common-sense constructs they have pre-selected and preinterpreted this world which they experience as the reality of their daily lives. It is these thought objects of theirs which determine their behaviour by motivating it. The thought objects constructed by the social scientist, in order to grasp this social reality have to be founded upon the thought objects constructed by the common-sense thinking of men, living their daily life within their social world. Thus, the constructs of the social sciences are, so to speak, constructs of the second degree, that is constructs made by actors on the social scene, whose behaviour the social scientist has to observe and explain in accordance with the procedural rules of his science" (I, 59).

As Charles Taylor would write in 1981 (p. 92-93),

But the big disanalogy with natural science lies in the nature of the commonsense understanding that theory challenges, replaces or extends. There is always a pre-theoretical understanding of what is going on among the members of a society, which is formulated in the descriptions of self and others which are involved in the institutions and practices of the society.

These methodological and social-epistemological differences between scientific domains are important because they affect the way in which knowledge utilisation occurs differently in different domains.

This concludes our discussion of some of the basic precepts (perhaps also assumptions) that underpin our model of knowledge production and utilisation, which is presented in the next section.

\subsection{A heuristic framework of knowledge production and utilisation Some basic distinctions}

Our point of departure in the framework proposed (Figure 3) is that scientific research or inquiry produces research outputs of two kinds: 'epistemic' or 'knowledge' outputs and 'non-epistemic' outputs or knowledge applications. Epistemic outputs include all forms of new knowledge: new theories, interpretations, insights, models, hypotheses, conjectures, facts, data as well as instrumentation.

Epistemic outputs (or 'new knowledge') in turn, can be divided into codified or embedded (or 'tacit') knowledge (see Section 4.4). Codified knowledge is knowledge that has been 'written up' and which is usually transmitted to a particular audience in a standard form such as a scientific presentation, paper, book, report, electronic communication and so on. Embedded knowledge refers to the knowledge (including skills, competencies) that is embedded in people. 
Non-epistemic outputs include all forms of application and technology that flow from the research process. These include process and product technologies and artefacts as well as social science applications such as policies, programmes, interventions, tests, scenarios, strategies, plans, systems, and many more.

In our earlier discussion we made the point that different modes of knowledge production have different intended or unintended audiences (or target groups, beneficiaries, user groups). We expand this principle in the framework by including (in the orange blocks) the most important audiences of research: the scientific community, the market/industry, society and government.

Finally, we also introduce in the framework reference to the various properties of research (outputs): volume or quantity, quality or merit, importance, marketability, utility or benefit and relevance. These six properties are often encountered in R\&D evaluation studies where the focus is on evaluating or assessing research in terms of one or more of its properties. Therefore, for instance, we might wish to assess the volume of research output of an individual scientist or centre over time. On the other hand, we might be interested in comparing the quality or merit of different scientists for purposes of promotion or funding through peer review.

\section{Figure 3: A framework of the production and utilisation of knowledge}

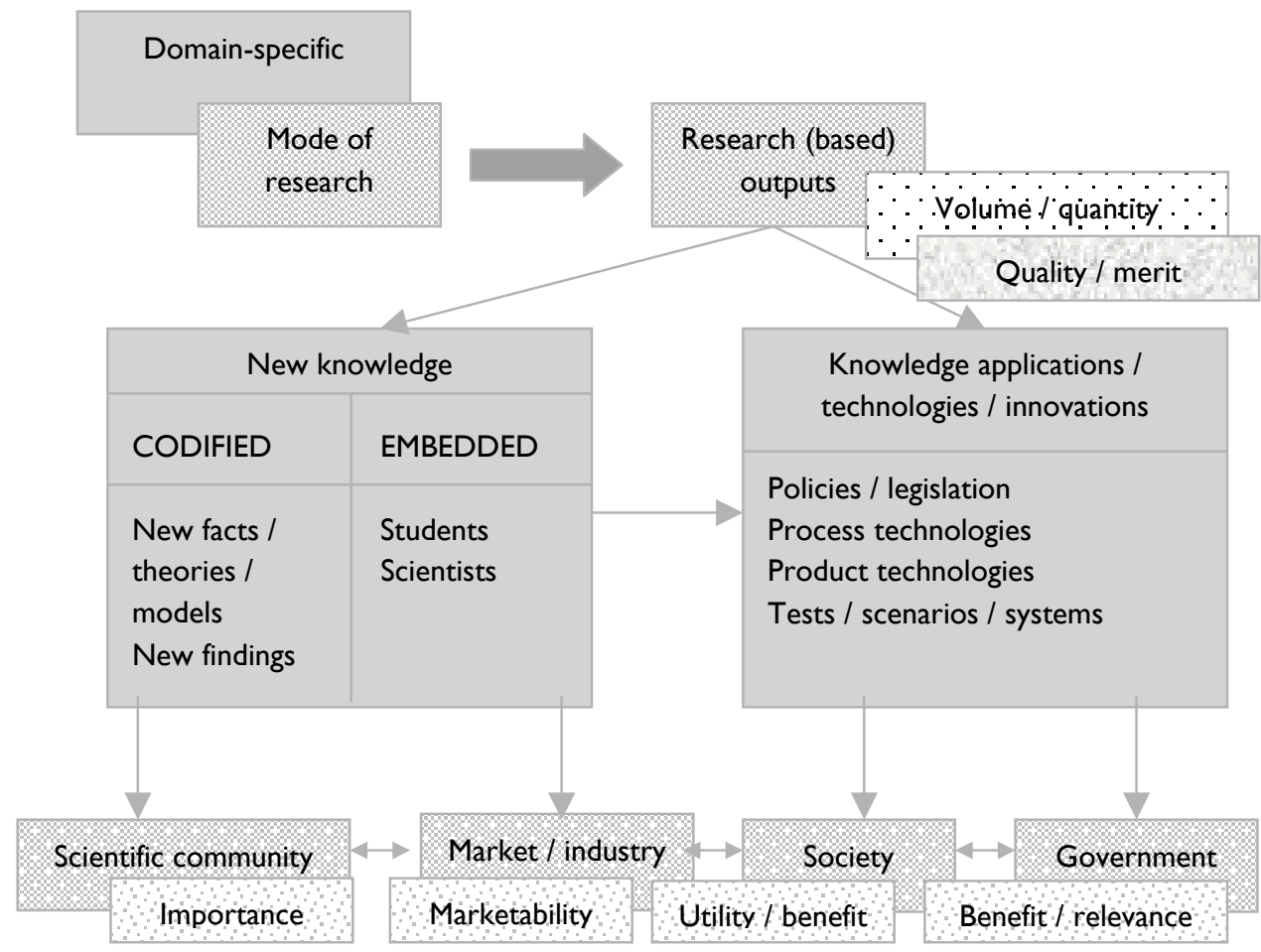


The focus in Figure 3 is on the generic context of knowledge production and knowledge application or utilisation. It emphasizes the following basic precepts about the dynamics of knowledge production (research) and utilisation (technological development and utilisation):

$<$ That R\&D manifests differently in different science domains

$<$ That research culminates both in epistemic and non-epistemic products

$<$ That different 'audiences' or 'interest-groups' place different expectations and demands on the R\&D process, and

$<$ That different criteria (quantity, quality, importance, utility, relevance) are applied within these different demand environments.

In the remainder of this chapter, we shift our attention to a specific model of technology transfer recently proposed by Barry Bozeman (2000). We first present Bozeman's model (which can be interpreted as a more specific case of the generic framework outlined in Figure 5.I). In a subsequent section, we introduce the notion of 'research utilisation trajectories' as an expansion of Bozeman's model to the process of research utilisation.

\section{The contingency effectiveness model of technology transfer (CETT)}

Bozeman's aim is to develop a model that explains the effectiveness of technology transfer processes. He refers to his model as the "contingency effectiveness model" because its main point is that technology transfer effectiveness "can have several meanings, including market impacts, political impacts, impacts on personnel involved and impacts on resources available for other purposes and other scientific and technical objectives" (2002:628).

In his review of the literature, Bozeman shows convincingly how the notions of 'technology' and 'technology transfer' are defined very differently in sociology, anthropology and management studies discourses, as well as according to the purpose of the research (our point about domain dependency). Bozeman also shows how debates about technology transfer in the US are tied directly to technology policy debates and paradigms. He distinguishes between three such policy paradigms (the market failure paradigm, the mission paradigm and the cooperative technology paradigm) and shows how the notion of 'technology transfer' means different things in each. Given the relevance of these distinctions to current debates in South Africa, it is worthwhile looking at each of these paradigms in some more detail.

The market failure technology policy paradigm is based on the premise that the market is the most efficient provider of goods and services and, left to its own devices, an unfettered market will lead to optimal rates of science production, technical change and economic growth. This implies that the government role in technology transfer should "chiefly be limited to removing barriers to the free market, through appropriate intellectual property policies, free trade agreements, neutral impact taxation and limited regulation of enterprise" (Bozeman, 2000:632). Within this paradigm, the role of universities and technikons is not as a broker of technology or commercial competitor, but as an educator and a provider of public domain research. This paradigm became dominant soon after the Second World War and remained the most dominant well into the eighties. 
The mission paradigm assumes that government should perform R\&D in the service of a well-specified mission in which there is a national interest which is not adequately covered by private R\&D. In the US, well known examples of such technology missions included the man on the moon project and defence related missions. In South Africa, we had comparable technology missions in the field of military and energy R\&D during the heyday of apartheid. The new R\&D strategy has identified such missions in the fields of advanced new materials, biotechnology and information and communication technology (ICT) R\&D. The role of universities and other key R\&D performers within the mission paradigm is to support major government initiatives. Government usually ploughs major resources into such missions and is able to marshal resources across a wide range of players in order to foster technology development and innovation within these demarcated domains.

Within the cooperative technology policy paradigm an active role is defined for government actors and universities in technology development and transfer. According to this view, government's role can be as one of the main research performers, including supplying applied research and technology to industry, or acting as a broker developing policies affecting industrial technology development. The cooperative technology paradigm "is an umbrella term for a set of values emphasizing cooperation among sectors” (idem: 632).

Strong proponents of the cooperative technology paradigm hold the view (sometimes seen to be controversial) that a government technology planning and coordinating role can augment productivity and innovation. As Bozeman indicates, a number of cooperative technology development policies attracted large attention in the US during the 1980s and 1990s (in challenging the market failure theory), including those pertaining to the use of federal laboratories as a partner in technology commercialisation, university-industry partnerships (including the science parks and company spin-off notions).

Within this paradigm, the role of universities and government laboratories is central. As Bozeman puts it:

The logic is simple: universities and government labs make, industry takes ... many policies involve co-production of technology and various forms of collaboration between industry and either government or universities. But the central point of cooperative technology policies is clear: putting universities and government laboratories to greater use as progenitors of technology and applied science (idem: 633).

After reviewing more recent lessons learnt about technology transfer and inter-sectoral cooperation, Bozeman then proceeds to present and explain the outlines of the "contingency effectiveness technology transfer" (CETT) model. The CETT model incorporates five main dimensions:

I) characteristics of the transfer agent;

2) characteristics of the transfer media,

3) characteristics of the transfer object,

4) the demand environment, and

5) characteristics of the transfer recipient (Cf. Figure 4). 
In Bozeman's own words: “... the model says that the impacts of technology transfer can be understood in terms of who is doing the transfer, how they are doing it, what is being transferred and to whom" (idem: 637). Table 5 elaborates on the dimensions and provides examples of each.

\section{Table 5: Dimensions of the CETT model}

\begin{tabular}{|l|l|l|}
\hline Dimension & Focus & Examples \\
\hline Transfer agent & $\begin{array}{l}\text { The institution or organization } \\
\text { seeking to transfer the technology }\end{array}$ & Government agency, university, firm \\
\hline $\begin{array}{l}\text { Transfer } \\
\text { medium }\end{array}$ & $\begin{array}{l}\text { The vehicle, formal or informal, } \\
\text { by which the technology is } \\
\text { transferred }\end{array}$ & $\begin{array}{l}\text { License, copyright, person-to- } \\
\text { person, formal scientific literature }\end{array}$ \\
\hline $\begin{array}{l}\text { Transfer } \\
\text { object }\end{array}$ & $\begin{array}{l}\text { The content and form of what is } \\
\text { transferred }\end{array}$ & $\begin{array}{l}\text { Scientific knowledge, technological } \\
\text { device, process, know-how and } \\
\text { specific characteristics of each }\end{array}$ \\
\hline $\begin{array}{l}\text { Transfer } \\
\text { recipient }\end{array}$ & $\begin{array}{l}\text { The organisation or institution } \\
\text { receiving the transfer object }\end{array}$ & $\begin{array}{l}\text { Firm, agency, consumer, user group, } \\
\text { institution and associated } \\
\text { characteristics }\end{array}$ \\
\hline $\begin{array}{l}\text { Demand } \\
\text { environment }\end{array}$ & $\begin{array}{l}\text { Factors (market and non-market) } \\
\text { pertaining to the need for the } \\
\text { transferred object }\end{array}$ & $\begin{array}{l}\text { Price for technology, substitutability, } \\
\text { relation to technologies now in use, } \\
\text { subsidy, market shelters }\end{array}$ \\
\hline
\end{tabular}

Figure 4: The contingency effectiveness model of technology transfer (CETT)

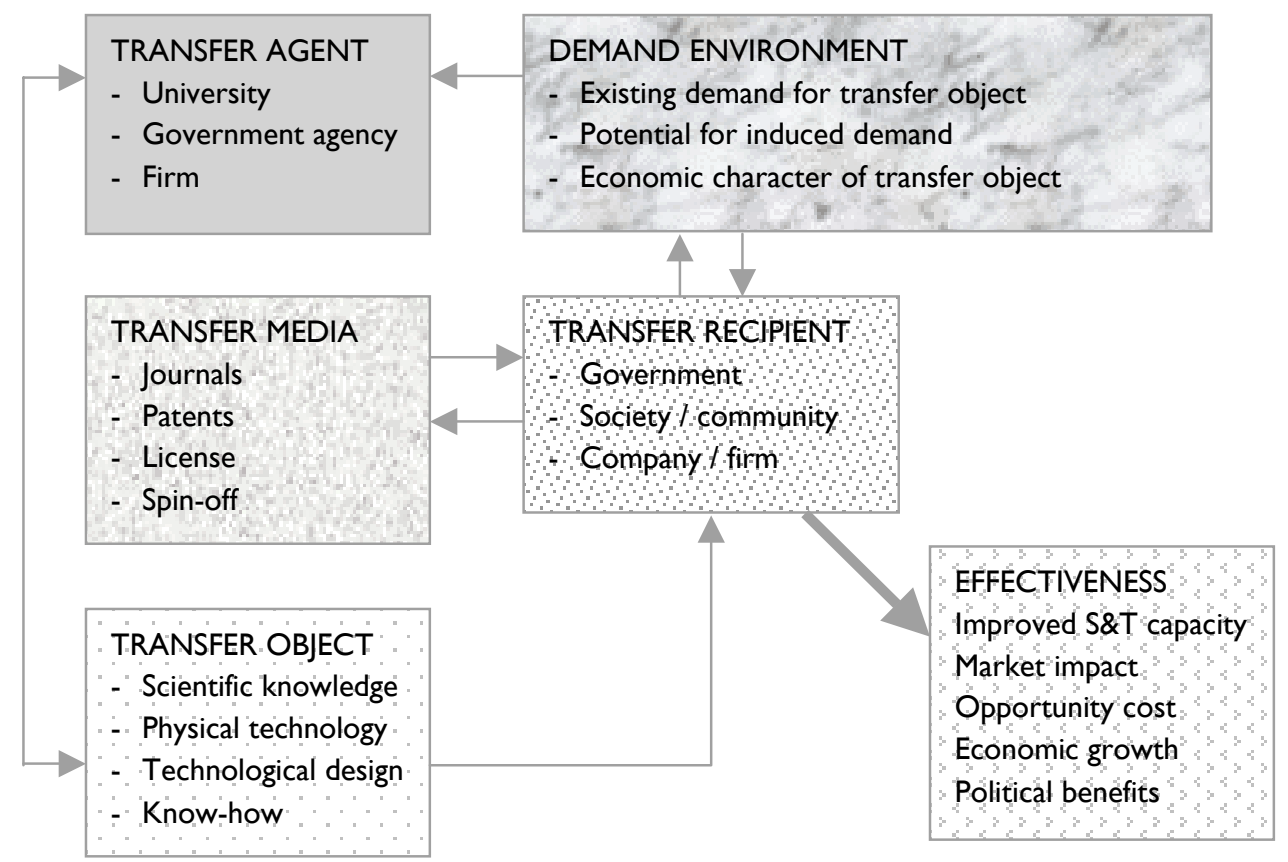


In the remainder of his review article, Bozeman discusses the main findings and lessons learnt from recent scholarship on each of these five dimensions. We summarise only some of the most salient conclusions that he draws.

I) Characteristics of the transfer agent

$<$ Etzkowitz $(1994,1998)$ focused on cultural changes within the new entrepreneurial university environment and shows a culture more conducive to industrially relevant work.

$<$ Various studies (e.g. Lee, 1996) found much less enthusiasm amongst university faculty for business partnerships.

$<$ Slaughter and Rhoades (1996) have focused on the effects of the cooperative paradigm on the structure of academic work, including salary distributions by field and faculty research choices. They suggest that more divisions - especially between the humanities and the natural sciences/engineering - are appearing because of these.

$<$ In earlier studies by Bozeman and Coker (1992) they found that three types of effectiveness related to the transfer agent:

Number of licenses related chiefly to the size of the lab; getting technologies out the door was best explained in terms of the missions of the laboratories and the composition of their R\&D; market impact, measured in terms of commercialized technology, was best explained by research diversity and degree of commercial orientation of the lab. (idem: 640)

2) Characteristics of the transfer medium

$<$ In a comprehensive study of transfer media, Roessner (1993) found that the most important category of interaction was contract research, followed by cooperative research. Few firms valued licensing and more formal interactions.

$<$ The verdict on science parks as a transfer medium remains ambiguous. In a recent study by Felsenstein (1994) it was found that location in a science park seems to provide no direct contribution to innovation but does confer status and prestige and these indirectly promote technology transfer and information flows.

$<$ Not surprisingly, numerous studies increasingly recognize the role of human capital and training in technology transfer. Bozeman refers, amongst others, to work by Bessant and Rush (1995) on consultants, the study of Hicks (1993) on personnel exchange and secondment, and his own work (Bozeman et al 1995) on informal relations among bench-level scientists.

3) Characteristics of the transfer object

< Grant and Gregory (1997) have analysed the transfer of 'tacit knowledge' - an area that is receiving new attention - and found that the extent of transfer of tacit knowledge often has a major impact on the effectiveness of manufacturing technology transfer. 
< An issue that has also received much attention is the extent to which transfer objects achieve commercialisation and what is their rate of commercial success. Various studies in the US (Roessner, 1993; Bozeman et al 1995, Geisler and Clements, 1995) have in fact shown that a minority of interactions are motivated by the prospect of directly realized commercial products. In addition, relatively few projects actually results in the company's commercialisation of technology transferred to the company.

$<$ Where commercialisation is successful, Bozeman (1997) has found that projects were more likely to lead to a commercialised product if they were initiated by either the companies' R\&D manager or by top managers in the company.

$<$ Interestingly enough, Rogers and Bozeman (1997) in a study on 219 federal laboratory-industry partnerships, found that projects which involved basic research had higher costs but also a greater likelihood of yielding a commercial technology project.

4) Characteristics of the demand environment

$<$ It is often assumed that the demand for technology is either market-push or market-pull. However, as Dalpe et al (1002) show, the role of the public sector as the first user of technological innovations is equally important.

$<$ In a study of technology transfer in the biomedical industry, Azzone and Maccarrone (1997) found that the critical demands for technologies and technical competencies is a major factor in determining market impact technology transfer success.

5) Characteristics of the transfer recipient

$<$ According to Bozeman, studies that have compared business and non-profit or government technology recipients have consistently found significant differences in process, barriers to effectiveness and indeed understandings of what count as effectiveness (Kingsley and Farmer, 1997).

$<$ There is evidence that the cooperative technology policy paradigm is taking hold - at least in the US. In their study interviewing companies' research directors and chief technical officers about sources of external technical knowledge, Roessner and Wise (1994) found that universities fared better than federal laboratories or other firms. However, with respect to sources of technical knowledge for new products and production processes, respondents rated in-house R\&D as most important, with universities and government agencies being ranked well below such sources as customers, competitors, suppliers and consultants.

In his final section, Bozeman discusses six effectiveness criteria: "Out of the door" transfer; market impact (e.g. on sales or profitability of the firm); economic development, political effects, opportunity costs and scientific and technical human capital. The advantages and disadvantages of each of these criteria are discussed. At the end of his review, Bozeman points out that despite hundreds of research studies on technology 
transfer over the recent decades, many topics are still neglected. Although we have learned much, we still know very little about many aspects of the technology transfer process. We quote him in full:

We still know almost nothing about technology transfer politics, including distributional outcomes of technology-based economic development. We have little understanding of many critical impacts, such as developments in scientific and technical human capital, occurring over long time periods. We know little about the impact of technology transfer activities on institutions, their designs and their full range of capabilities. (2000:650)

This concludes our rather detailed discussion of Bozeman's CETT model. In the final section, we present an adapted version of the model and introduce the notion of RUTT research utilization trajectory.

\section{A modified version of the CETT model}

Bozeman himself points to the fact that the terms 'technology transfer' and 'knowledge transfer' are often used loosely and interchangeably. Following on the basic precepts formulated above, we propose a more generic version of CETT that can in fact be applied to all forms of knowledge transfer. We believe that the same five dimensions that apply to technology transfer can be applied to the transfer of all forms of knowledge. We have argued that technological knowledge or knowledge applications is one form of research output - non-epistemic output. We don't think that there is any plausible reason why the transfer of different forms of knowledge (theoretical/ empirical/technological) would not conform to the same logic. The basic structure and logic of the production and utilisation of knowledge which was outlined in Figure 5.I, we would argue, is adequately captured in the more dynamic perspective of the CETT model.

However, we do suggest one refinement or modification to the CETT model that derives from our slightly larger perspective on the processes of knowledge utilisation and knowledge production. One of the assumptions that underlie Figure 5.I is that the mode of research does affect the mode of research utilisation. To capture the fact that different modes of research can and indeed do influence the way in which research outputs are utilised differently, we introduce the notion of 'research utilisation trajectories' (RUTTs). A RUTT depicts the more specific pattern of utilisation (including dissemination and diffusion) of research that is related to differences in modes of research. At least three types of RUTTs can be distinguished: the basic research utilisation trajectory (Figure 5), an applied research utilisation trajectory (Figure 6) and a (technology) development utilisation trajectory. The latter is not discussed separately because it is in fact identical to the technology transfer model discussed by Bozeman.

This expansion of the CETT model suggests that it would be more appropriate to refer to it as the contingency effectiveness knowledge transfer model (CEKT), of which technology transfer is one limiting case and basic and applied research are others. 
Figure 5: The basic research utilisation trajectory

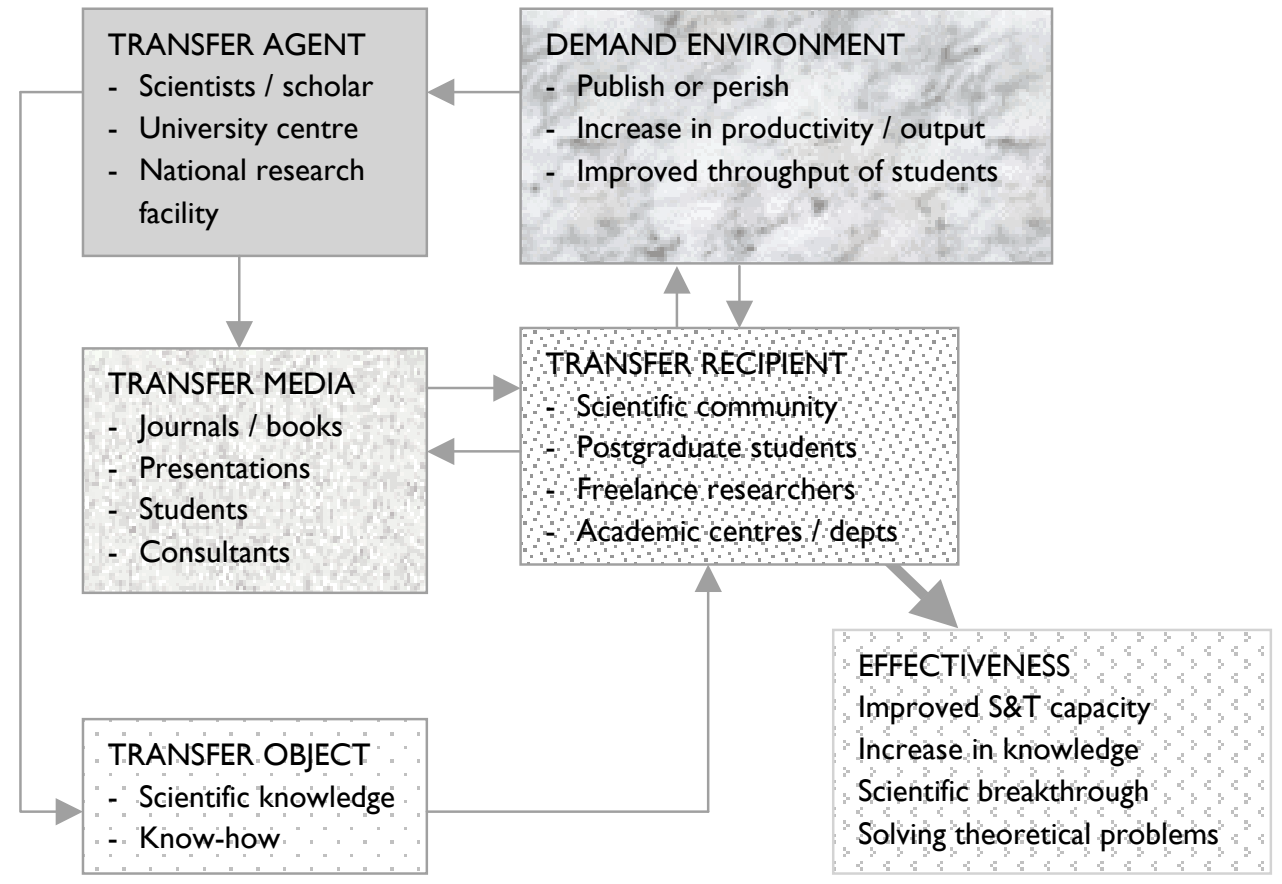

Figure 6: The applied research utilisation trajectory

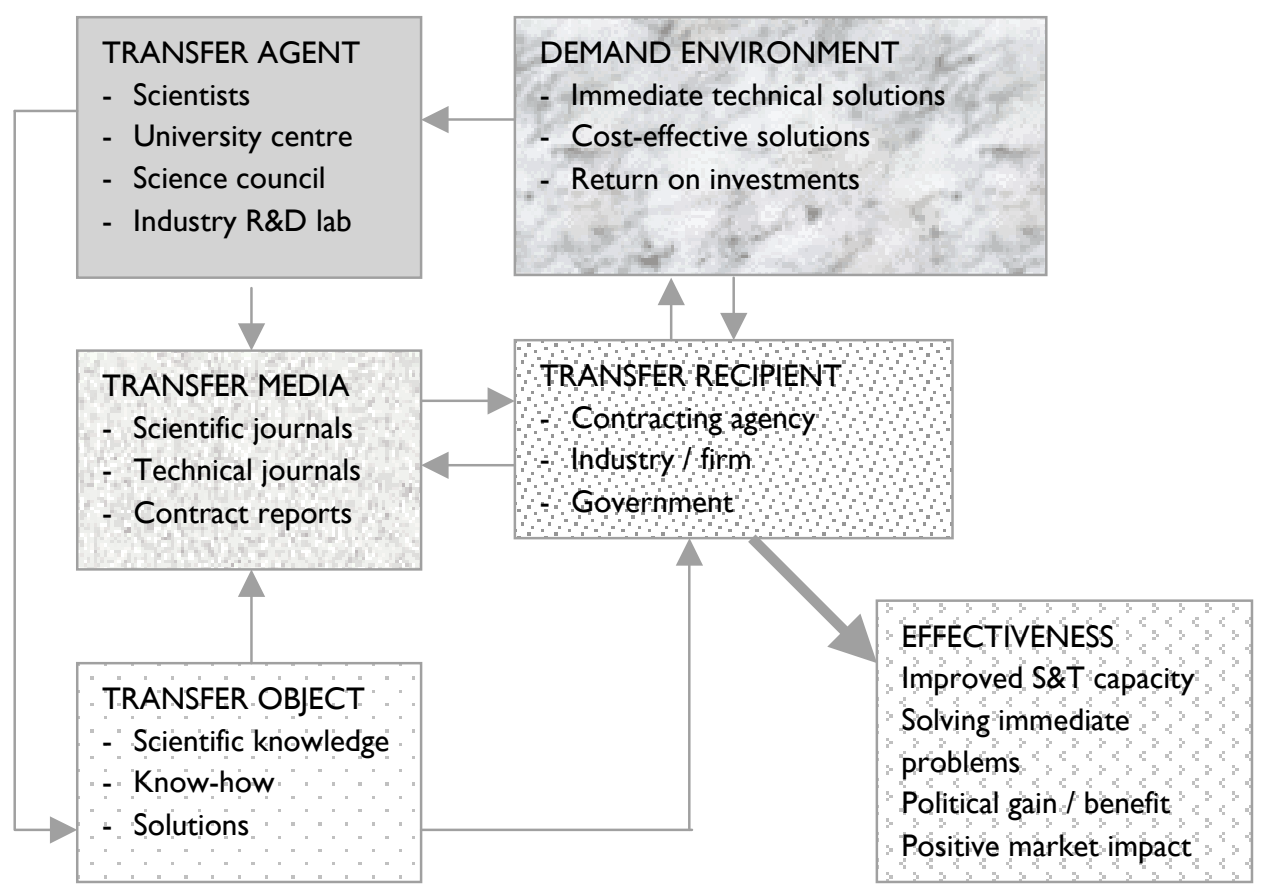


In summary, the contingency effectiveness knowledge transfer (CEKT) framework outlined above highlights the following aspects of knowledge utilization:

$<$ The ways in which (scientific) knowledge are utilised depend both on the modes of knowledge production (basic, applied, strategic, developmental) and the scientific domain.

$<$ Scientific research produces two kinds of outputs: epistemic products (new knowledge) and non-epistemic products (knowledge applications, technologies). This means that the utilisation of knowledge includes both the application and use of research findings (epistemic) and research-based products (non-epistemic).

$<$ The CEKT-framework identifies five dimensions that are present in all knowledge utilisation (or transfer) processes: the transfer agent, the transfer medium, the transfer object, the transfer recipient and the demand environment. The ultimate effectiveness of knowledge utilisation depends on the peculiar interplay of each of these dimensions.

$<$ The CEKT-framework also introduces the notion of 'research utilisation trajectories' (RUTTs). The notion of a RUTT captures the unique dynamics of the utilisation of research within different paths or trajectories. It highlights the fact that the peculiar dynamics within each of the 'basic research utilisation trajectory' 'applied research utilisation trajectory' and 'technology development trajectory' is sufficiently different to necessitate a more differentiated treatment of knowledge utilisation issues. 


\section{LIST OF REFERENCES}

Albæk E (1995) Between knowledge and power: Utilization of social science in public policy-making, Policy Sciences, 28:79-100.

Alic J et al (1992) Beyond Spin-off: Military and Commercial Technologies in a Changing World. Harvard College, Cambridge MA.

Azzone G \& Maccarrone P (1997) The emerging role of lean infrastructures in technology transfer: The case of the Innovation Plaza project, Technovation, I7(7):391-402.

Backer TE (199I) Knowledge utilization: The third wave, Knowledge: Creation, Diffusion, Utilization, 12(3):225-240.

Balázs K (1996) Academic entrepreneurs and their role in 'knowledge' transfer. Brighton: SPRU.

Bell S \& Sadlak J (1992) Technology transfer in Canada: Research parks and centres of excellence, Higher Education Management, 4(2):227-244.

Berggren AC (200I) Understanding about Swedish midwives' utilization of research-based knowledge.. Paper presented at the HSS Conference, 200I.

Bessant J \& Rush H (1995) Building bridges for innovation: The role of consultants in technology transfer, Research Policy, 24(I):97-II5.

Beyea SC \& Nicoll LH (1997) Research corner, The Association of Perioperative Registered Nurses Journal. Online at http://www.aorn.org/journal/research/rc397.htm

Beyer JM \& Trice HM (1982) The utilization process: A conceptual framework and synthesis of empirical findings, Administrative Science Quarterly, 27:591-622.

Bonaccorsi A \& Piccaluga A (1994) A theoretical framework for the evaluation of university-industry relationships, $R \& D$ Management, 24(3):229-247.

Bozeman B (1997) Commercialization of federal laboratory technology: Results of a study of industrial partners. In New Technology-Based Firms in the 1990s, edited by RP Oakey. Volume 3. London: Paul Chapman Publishing.

Bozeman B (2000) Technology transfer and public policy: A review of research and theory, Research Policy, 29:627-655.

Bozeman B \& Coker K (1992) Assessing the effectiveness of technology transfer from US government R\&D laboratories: The impact of market orientation, Technovation, 12(4):239-255.

Bozeman B, Papadakis M \& Coker K (1995) Industry perspectives on commercial interactions with federal laboratories: Does the cooperative technology paradigm really work? Report to the National Science Foundation. Research on Science and Technology Program, January.

Brooks H (1996) The evolution of U.S. science policy, In Technology, R\&D, and the economy, edited by BLR Smith \& CE Barfield. Washington DC: The Brookings Institution.

Bulmer M (1982) The uses of social research: Social investigation in public policy-making. Contemporary Social Research, No. 3. London: George Allen \& Unwen.

Carstens A \& Mouton J (2002) Industry - higher education partnerships: Literature review. Stellenbosch: Centre for Interdisciplinary Studies, University of Stellenbosch.

Centre for Knowledge Transfer (CKT) web site (2002). Online at http://www.nursing.ualberta.ca/knowledgetransfer/about.html 
Clarke HF (1995) Using research to make a difference in clinical nursing practice: The Nightingale legacy. Paper presented to the International Paediatric Nursing Conference, 2 June 1995. Online at http://classweb.gmu.edu/rfeeg/ichna/clarke.html

Cohen WM, Florida R, Randazzese L \& Walsh J (1998) Industry and the academy: Uneasy partners in the cause of technological advance, In Challenges to research universities, edited by RG Noll. Washington DC: Brookings Institution Press.

Cohen WM \& Levinthal DA (1990) Absorptive capacity: A new perspective on learning and innovation, Administrative Science Quarterly, 35:I28- 152.

Coutts JA (1995) Agricultural extension policy as a framework for change, Journal of Agricultural Education and Extension, 2(I): 17-28. Online at http://www.bib.wau.nl/ejae/v2nl-3.html

Cozzens S, Healey P, Rip A \& Ziman J (199I) The research system in transition. Dordrecht: Kluwer Academic Publishers.

Dalpe R, DeBresson C \& Xiaoping H (1992) The public sector as first user of innovations, Research Policy, 2 I (3):25I.

Department of Labour web site (2002). Online at http://www.labour.gov.za/docs/mycareer/alphabet/a/agriexten.html

Dobbins $M$ (1998) Dissemination and use of research evidence for policy and practice by nurses: A model of development and implementation strategies. Paper prepared for the Dissemination and Utilization Model Advisory Committee, 3I January 1998.

Estabrooks CA (1999) The conceptual structure of research utilization, Research in Nursing and Health, 22:203-216.

Etzkowitz $\mathrm{H}$ (1994) Knowledge as property: MIT and the debate over academic patent policy. Minerva, Winter.

Etzkowitz H (1998) The norms of entrepreneurial science: cognitive effects of the new university-industry linkages, Research Policy, 27:823-833.

Etzkowitz H \& Webster A (1998) Entrepreneurial science: The second academic revolution, In Capitalizing knowledge: New intersections of industry and academia, edited by H Etzkowitz, A Webster \& P Healey. Albany: State University of New York Press.

Etzkowitz H \& Stevens AJ (1998) Inching toward industrial policy: The university's role in government initiatives to assist small, innovative companies in the United States, In Capitalizing knowledge: New intersections of industry and academia, edited by $\mathrm{H}$ Etzkowitz, A Webster \& P Healey. Albany: State University of New York Press.

Etzkowitz $\mathrm{H}$ et al (2000) The evolution of the entrepreneurial university, In The future of knowledge production in the academy, edited by $M$ Jacob \& $T$ Hellström.

Buckingham: Open University Press.

Evidence-Based Health Care Project (EBHCP) web site (2002), University of Minnesota. Online at http://evidence.ahc.umn.edu/ebn.htm

Felsenstein D (1994) University-related science parks: Seedbeds or enclaves of innovation, Technovation, I4(2):93-I 10.

Geisler E \& Clements C (1995) Commercialization of technology from federal laboratories: The effects of barriers, incentives and the role of internal entrepreneurship. Final Report to the National Science Foundation. Department of Management, University of Wisconsin-Whitewater, Whitewater, WI. 
Gibbons M, Limoges C, Nowotny H, Schwartzman S, Scott P \& and Trow M (1994) The new production of knowledge: The dynamics of science and research in contemporary societies. London: Sage.

Grant EB \& Gregory MJ (1997) Tacit knowledge, the life cycle and international manufacturing transfer, Technology Analysis \& Strategic Management, 9(2): 149-I6I.

Hicks D (1993) University-industry links in Japan, Policy Sciences, 26(4):36 I-395.

Hicks D (1999) Six reasons to do long-term research, Research \& Technology Management, 42(4):8-II.

Hodgkins EA (1989) NCHRP Synthesis of Highway Practice 150: Technology Transfer in Selected Highway Agencies. TRB, National Research Council, Washington DC.

Hughes J (1990) The philosophy of social research. Second edition. London: Longman

Independent Living Research Utilization (ILRU) web site (2002). Online at http://www.ilru.org/ilru-overview.html

Johnstad T (1987) Science parks: Strategic options of universities, International Journal of Institutional Management in Higher Education, I I (3):294-302.

Jones GE \& Garforth C (1997) The history, development, and future of agricultural extension, In Improving agricultural extension: A reference manual, edited by BE Swanson, RP Bentz and AJ Sofranko. Rome: Food and Agriculture Organization.

Kash DE, Auger RN \& Li N (2002) Organizational requirements for the innovation of complex technologies, In Networks, alliances and partnerships in the innovation process, edited by J de la Mothe \& AN Link. Boston: Kluwer Academic Publishers.

Kingsley G \& Farmer MC (1997) Using technology absorption as an evaluation criterion: Case studies from a state research and development program, Policy Studies Journal, 25(3):436-450.

Kline S \& Rosenberg N (1986) An overview of innovation, In The Positive Sum Strategy: Harnessing Technology for Economic Growth, edited by R Landau \& N Rosenberg. Washington DC: National Academy Press.

Kline S (199la) Models of innovation and their policy consequences, In Japanese/American Technological Innovation, edited by D Kingery. New York: Elsevier.

Kline S (199/b) Styles of innovation and their cultural basis, Chemtech, August 199I.

Knowledge Utilization Studies in Practice (KUSP) web site (2002). Online at http://www.nursing.ualberta.ca/estabrooks/kusp/

Kraak A (1997) Globalisation, changes in knowledge production, and the transformation of higher education, In Knowledge, identity and curriculum transformation in Africa, edited by $\mathrm{N}$ Cloete, J Muller, MW Makgoba \& D Ekong. Cape Town: Maskew Miller Longman.

Krull R (1990) OECD Seminar on Technology Transfer and Adaptability in Industrialized Nations. Summary report. University of Florida Transportation Research Center

Lee YS (1996) 'Technology transfer' and the research university: A search for the boundaries of university-industry collaboration, Research Policy, 25(6):843-863

Leydesdorff L \& Etzkowitz H (1998) The Triple Helix as a model for innovation studies.

(Conference report). Online at http://home.pscw.uva.nl/lleydesdorff/th2/spp.htm

Lundvall B-Å \& Borrás S (1997) The globalising learning economy: Implications for innovation policy. Luxembourg: European Communities.

Martino JP (1996) The role of university research institutes in technology transfer, Industry \& Higher Education, I0(5):3 16-320. 
Mustar P (1998) Partnerships, configurations and dynamics in the creation and development of SMEs by researchers. Industry \& Higher Education, August, Pp2 17-22I.

Nagel UJ (1997) Alternative approaches to organizing extension, In Improving agricultural extension: A reference manual, edited by BE Swanson, RP Bentz and AJ Sofranko. Rome: Food and Agriculture Organization.

National Association of State Universities and Lang-Grant Colleges (NASULGC) (1995) The land-grant tradition. Online at http://www.nasulgc.org/publications/Land_Grant/Land_Grant_Main.htm

National Center for the Dissemination of Disability Research (NCDDR) (1998) A review of the literature on dissemination and knowledge utilization. Southwest Educational Development Laboratory. Online at http://www.ncddr.org/du/products/review/index.html

National Center for the Dissemination of Disability Research (NCDDR) web site (2002). Online at http://www.ncddr.org/

National Research Council (1995) Colleges of agriculture at the land grant universities: A profile. Committee on the Future of the Colleges of Agriculture in the Land Grant System.

Neilson S (200I) Knowledge utilization and public policy processes: A literature review. Canada: International Development Research Centre.

Nilsson K \& Sunesson S (1993) Strategy and tactics: Utilization of research in three policy sector contexts, The Journal of Applied Behavioral Science, 29(3):366-383.

OECD (I99I) Oslo Manual: Proposed guidelines for collecting and interpreting technological innovation data. Paris: OECD.

OECD (1994) Frascati Manual 1993. Proposed standard practice for surveys of research and experimental development. Paris: OECD.

OECD (I996) The knowledge-based economy. Paris: OECD.

OECD (2000) Policy brief: Science, technology and innovation in the new economy. Paris: OECD.

OECD (2002) Bench-marking industry-science relationships. Paris: OECD.

Penzhorn KEW (1987) Die geskiedkundige ontwikkeling van die staats-voorligtingsdiens in South Africa, South African Society for Agricultural Extension, Anniversary Publication 1966-1987.

Peters LS \& Etzkowitz H (1990) University-industry connections and academic values, Technology in Society, 12:427-440.

Rip A (1994) The republic of science in the 1990s, Higher Education 28:3-23.

Rip A (1997) A cognitive approach to relevance of science, Social Science Information 36(4):615-640.

Roessner JD (1993) What companies want from the federal labs, Issues in Science \& Technology, I0(I):37-42.

Roessner JD \& Wise A (1994) Public-policy and emerging sources of technology and technical-information available to industry, Policy Studies Journal, 22(2):349-358.

Rogers J \& Bozeman B (1997) Basic research and technology transfer in federal laboratories, 22(3):37-48.

Ruivo B (1994) Paradigms: 'Phrases' or' paradigms' of science policy?, Science and Public Policy, Vol. 21 , No. 3, p. I57-I64 
Rutledge DN (1995) Research utilization in oncology nursing, Oncology Nursing Updates: Patient Treatment and Support, 2(4).

Saaiman BF (1998) Ligdraers deur die jare, Elsenburg Journal, Commemorative Edition.

Sadlak J (1992) New reality in university-industry relations: A search for foundations and forms, Interchange, 23(I-2): I I I- I 22.

Salter A et al (2000) Talent, not technology: The impact of publicly funded research on innovation in the UK. Sussex: Science and Technology Policy Research Unit.

Sangonet web site (2002) Online at http://www.sn.apc.org/sangonet/environment/ngo_rura.html

Schmitt RP, Beimborn EA \& Mulroy MJ (1985) Technology transfer primer. Report FHWATS-84-226. University of Wisconsin.

Scott A, Steyn G, Geuna A, Brusoni S \& Steinmueller E (200I) The economic returns to basic research and the benefits of university-industry relationships: $A$ literature review and update of findings. Report to the Office of Science and Technology by SPRU Science and Technology Policy Research.

Senker J, Faulkner W \& Velho L (1998) Science and technology flows between industrial and academic research: A comparative study, In Capitalizing knowledge: New intersections of industry and academic, edited by $\mathrm{H}$ Etzkowitz, A Webster \& $\mathrm{P}$ Healey. Albany: State University of New York Press, pp I I I-I 32.

Shove E (2000) Reciprocities and reputations: New currencies in research, In The future of knowledge production in the academy, edited by M Jacob \& T Hellström.

Buckingham: Open University Press.

Slaughter S \& Leslie LL (1997) Academic capitalism: Politics, policies, and the entrepreneurial university. Baltimore: The Johns Hopkins University Press.

Slaughter S \& Rhoades G (1996) The mergence of a competitiveness research-anddevelopment policy coalition and the commercialisation of academic science and technology, Science, Technology \& Human Values, 21 (3):303-339.

Smith BLR \& Barfield CE (1996) Contributions of research and technical advance to the economy, In Technology, R\&D, and the economy, edited by BLR Smith \& CE Barfield. Washington DC: The Brookings Institution.

South African Institute for Agricultural Extension web site (2002). Online at http://www.up.ac.za/academic/ecoagric/prg_agextindex.htm

Stankiewicz R (1998) Science parks and innovation centres, In Capitalizing knowledge: New intersections of industry and academia, edited by $\mathrm{H}$ Etzkowitz, A Webster \& $\mathrm{P}$ Healey. Albany: State University of New York.

Stetler CB (1985) Research utilization: Defining the concept, Image: Journal of Nursing Scholarship, 17(2):40-44.

Stetler CB (200I) Updating the Stetler Model of research utilization to facilitate evidencebased practice, Nursing Outlook, 49(6):272-279.

Tolbert TL (1985) Industry/university research cooperation: Convenience or necessity the industrial view, Journal of the Society of Research Administrators, 17(2):45-52.

Waardenburg G (200I) The utilization of research results at the Ministry of Foreign Affairs: Points of departure, In Utilization of Research for Development Cooperation: Linking knowledge production to development policy and practice. The Hague:

Netherlands Development Assistance Research Council.

Walshok ML (1995) Knowledge without boundaries: What America's research universities can do for the economy, the workplace, and the community. San Francisco: Jossey-Bass 
Western Cape Department of Agriculture (WCDA) web site (2002). Online at http://www.elsenburg.com/

Weiss $\mathrm{CH}$ (1978) Broadening the concept of research utilization. Sociological Symposium, 21:22.

Wolfe DA \& Lucas M (200I) Investing knowledge in universities: Rethinking the firm's role in knowledge transfer, In Knowledge management in the innovation process, edited by J de la Mothe \& D Foray. Boston: Kluwer Academic Publishers. 

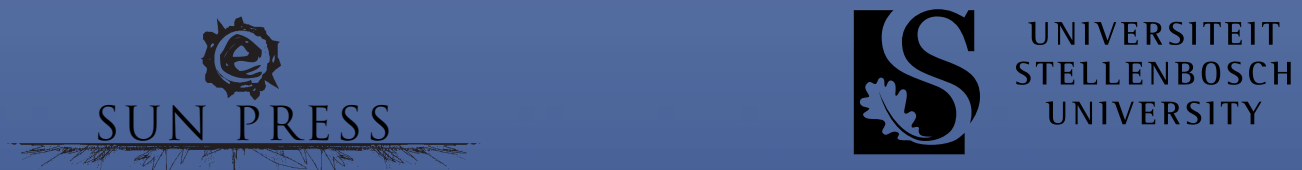